Western University

Scholarship@Western

Chemistry Publications

Chemistry Department

Summer 7-2-2016

Synthesis, Characterization, and Pre-Ceramic Properties of $\pi$-Conjugated Polymers Based on $\mathrm{Ni}$ (II) Complexes of Goedken's Macrocycle

Joseph A. Paquette

Joe Gilroy

jgilroy5@uwo.ca

Follow this and additional works at: https://ir.lib.uwo.ca/chempub

Part of the Chemistry Commons

Citation of this paper:

Paquette, Joseph A. and Gilroy, Joe, "Synthesis, Characterization, and Pre-Ceramic Properties of $\pi$-Conjugated Polymers Based on $\mathrm{Ni}(\mathrm{II})$ Complexes of Goedken's Macrocycle" (2016). Chemistry Publications. 76.

https://ir.lib.uwo.ca/chempub/76 


\title{
Synthesis, Characterization, and Pre-Ceramic Properties of $\pi$-Conjugated Polymers Based on Ni(II) Complexes of Goedken's Macrocycle
}

\author{
Joseph A. Paquette and Joe B. Gilroy* \\ Department of Chemistry and the Centre for Advanced Materials and Biomaterials Research (CAMBR), The University of Western \\ Ontario, 1151 Richmond St. N., London, Ontario, Canada, N6A 5B7.
}

Correspondence to: Joe B. Gilroy (E-mail: joe.gilroy@uwo.ca)

\begin{abstract}
Nickel(II) complexes of Goedken's macrocycle bearing alkyne substituents were copolymerized with 2,7-dibromo9,9-dihexylfluorene, 2,5-dibromo-3-hexylthiophene, and 1,4-dibromo-2,5-bis(hexyloxy)benzene via microwave-induced Sonogashira cross-coupling reactions to produce copolymers $6 \mathrm{~F}, 6 \mathrm{~T}$, and $6 \mathrm{~B}$. The spectroscopic and electrochemical properties of the copolymers were examined and compared to model compounds. Specifically, each polymer exhibited a nickel-based absorption centered at ca. $589 \mathrm{~nm}$ and two $\pi \rightarrow \pi^{*}$ transitions between 272 and $387 \mathrm{~nm}$. While the copolymers did not exhibit extended $\pi$ conjugation, the nature of the organic spacer did affect the high energy transitions. Furthermore, each copolymer underwent two ligand-based one-electron oxidations at potentials of ca. $0.24 \mathrm{~V}$ and ca. $0.75 \mathrm{~V}$ relative to the ferrocene/ferrocenium redox couple. Post-polymerization functionalization of the alkyne group in $6 \mathrm{~F}$ with $\mathrm{Co}_{2}(\mathrm{CO})_{8}$ afforded a novel heterobimetallic copolymer that yielded amorphous nanomaterials containing $\mathrm{Ni} / \mathrm{Co}$ when pyrolyzed at $800{ }^{\circ} \mathrm{C}$ for $3 \mathrm{~h}$ under an atmosphere of $\mathrm{N}_{2} / \mathrm{H}_{2}(95: 5)$.
\end{abstract}

KEYWORDS: Metallopolymers, pyrolysis, $\pi$-conjugated polymers, metal alloys, macrocyclic ligands, post-polymerization functionalization

INTRODUCTION Metallopolymers, ${ }^{1-10}$ which combine the processability of macromolecules and the properties of transition metals, are an intriguing class of functional materials. As a result of these combined traits, metallopolymers have been used extensively, for example, as redox-active, ${ }^{11-16}$ magnetic, ${ }^{17-}$ 22 and luminescent materials. ${ }^{23-27}$

The introduction of metals into $\pi$-conjugated polymer frameworks affords the ability to further expand their functionality. ${ }^{28-34}$ One of the most well-studied classes of $\pi$ conjugated metallopolymers are metal-polyynes. ${ }^{30,35-38}$ Wong and co-workers have previously described platinum-based systems (e.g., 1) with $\pi$-conjugation along the polymer backbone and demonstrated their utility in photovoltaic devices $^{37}$ and as pre-ceramic materials. ${ }^{38-40}$ Another widely explored family of polymers based on $\pi$-conjugated units contain porphyrins and phthalocyanine complexes. ${ }^{41-45}$ For example, Paik and co-workers realized a $\mathrm{Cu}(\mathrm{II})$-containing phthalocyanine polymer (2) via intramolecular macrocyclization reactions in order to create single chain nanoparticles. ${ }^{45} \pi$-Conjugated metallopolymers composed of Schiff bases coordinated to transition metals have also shown widespread utility. ${ }^{28,46-53}$ Notably, Swager and colleagues have reported polymers based on salen ligands coordinated to cobalt (e.g., $\mathbf{3})$ and demonstrated their utility as nitric oxide sensors. ${ }^{48-}$ 49

Most metallopolymers contain one metal atom in their repeating unit, which can limit their utility in some applications, including as pre-ceramic materials. The introduction of additional transition metal atoms to polymer scaffolds can afford highly metallized polymers. ${ }^{38,54-58}$ One such example was synthesized by Manners and co-workers, where molybdenum cyclopentadienyl $(\mathrm{Cp})$ carbonyl was used to append two $\mathrm{MoCp}(\mathrm{CO})_{2}$ groups to each repeating unit of the backbone of a polyferrocenylsilane (4) to produce metallopolymers with utility in UV-photolithography applications. ${ }^{54}$

Herein, we build on our previously communicated results ${ }^{59}$ by presenting an expansion of a series of $\pi$-conjugated polymers containing $\mathrm{Ni}$ (II) complexes of Goedken's macrocycle and their comprehensive characterization, including comparison to model compounds. These copolymers have been specifically

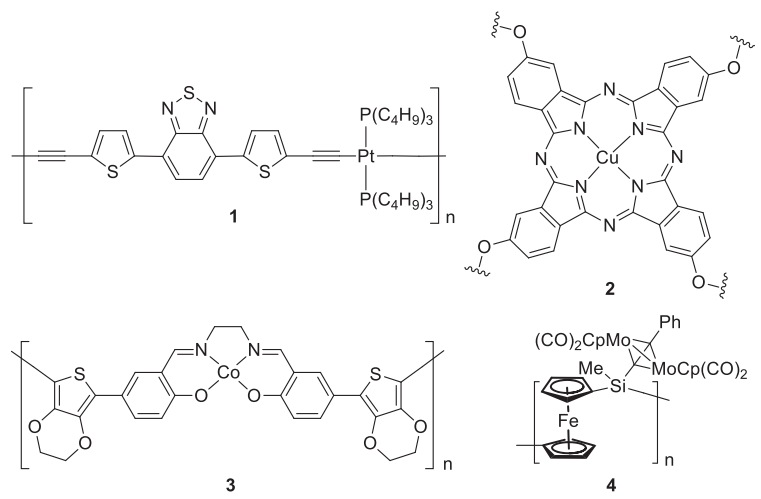


targeted in an effort to combine the redox and charge transfer properties of $\mathrm{Ni}(\mathrm{II})$-complexes of Goedken's macrocycle ${ }^{60-61}$ with common traits associated with $\pi$-conjugated organic polymers (e.g., low band-gaps, charge transport properties). ${ }^{28,35,62} \quad$ Furthermore, we describe postpolymerization reactions used to transform one of the copolymers into a heterobimetallic polymer and its use as a preceramic material.

\section{EXPERIMENTAL}

\section{General Considerations}

All reactions and manipulations were carried out under a nitrogen atmosphere using standard Schlenk or glove box techniques unless otherwise stated. Solvents were obtained from Caledon Laboratories, dried using an Innovative Technologies Inc. solvent purification system, collected under vacuum, and stored under a nitrogen atmosphere over $4 \AA$ molecular sieves. Reagents were purchased from SigmaAldrich, Alfa Aesar, or Oakwood Chemical and used as received unless otherwise stated. 4-[(trimethylsilyl)ethynyl]benzoyl chloride, ${ }^{63}$ tetramethyldibenzo-tetraaza[14]annulene nickel(II) ${ }^{64}$ 2,7-dibromo-9,9-dihexylfluorene, ${ }^{65}$ 2-bromo-9,9dihexylfluorene, ${ }^{65} \mathbf{5},{ }^{59} \mathbf{6 F},{ }^{59} \mathbf{9},{ }^{59}$ and $\mathbf{1 2}^{59}$ were prepared according to previously published protocols.

NMR Spectra were recorded on a $600 \mathrm{MHz}\left({ }^{1} \mathrm{H}: 599.3 \mathrm{MHz}\right.$, $\left.{ }^{13} \mathrm{C}: 150.7 \mathrm{MHz}\right)$ Varian INOVA instrument or a $400 \mathrm{MHz}\left({ }^{1} \mathrm{H}\right.$ $400.1 \mathrm{MHz},{ }^{13} \mathrm{C}: 100.6 \mathrm{MHz}$ ) Varian Mercury instrument. ${ }^{1} \mathrm{H}$ NMR spectra were referenced to residual $\mathrm{CHCl}_{3}(7.27 \mathrm{ppm})$ and ${ }^{13} \mathrm{C}$ NMR spectra were referenced to $\mathrm{CDCl}_{3}$ (77.0 ppm). Mass spectrometry data were recorded in positive-ion mode with a Bruker microTOF II instrument using electrospray ionization. UV-vis absorption spectra were recorded in $\mathrm{CH}_{2} \mathrm{Cl}_{2}$ solutions using a Cary 300 Scan instrument. Four separate concentrations were run for each sample and molar extinction coefficients were determined from the slope of a plot of absorbance against concentration. FT-IR spectra were recorded on a PerkinElmer Spectrum Two instrument using an attenuated total reflectance accessory. Powder XRD diffractograms were acquired using an Inel CPS powder diffractometer with an Inel XRG 3000 generator and Inel CPS 120 detector using a $\mathrm{CuK} \alpha$ radiation source.

\section{Microwave Reactions}

Microwave reactions were carried out in a $400 \mathrm{~W}$ Biotage Initiator 2.0 microwave reactor. A $5 \mathrm{~mL}$ glass vial was charged with the relevant solid or degassed liquid reagents/solvents, sealed in an inert atmosphere glove box, and subjected to microwave irradiation as described below.

\section{Gel Permeation Chromatography (GPC)}

GPC experiments were conducted in chromatography-grade THF at concentrations of $5 \mathrm{mg} \mathrm{mL}^{-1}$ using a Viscotek GPCmax
VE 2001 GPC instrument equipped with an Agilent PolyPore guard column (PL1113-1500) and two sequential Agilent PolyPore GPC columns packed with porous poly(styrene-codivinylbenzene) particles (MW range: 200-2,000,000 $\mathrm{g} \mathrm{mol}^{-1}$; PL1113-6500) regulated at a temperature of $30{ }^{\circ} \mathrm{C}$. Signal responses were measured using a Viscotek VE 3580 RI detector, and molecular weights were determined by comparison of the maximum RI response with a calibration curve (10 points, 1,500-786,000 $\mathrm{g} \mathrm{mol}^{-1}$ ) established using monodisperse polystyrene standards purchased from Viscotek.

\section{Thermal Analysis and Pyrolysis Studies}

Thermal degradation studies were performed using a TA Instruments Q50 TGA. Samples were placed in an alumina cup and heated at a rate of $10^{\circ} \mathrm{C} \mathrm{min}^{-1}$ from 25 to $800 / 1000{ }^{\circ} \mathrm{C}$ under a flow of nitrogen $\left(60 \mathrm{~mL} \mathrm{~min}^{-1}\right)$. Differential scanning calorimetry (DSC) traces were acquired on a TA Instruments DSC Q20 instrument. The polymer samples were placed in an aluminum $\mathrm{T}_{\text {zero }}$ pan and heated from room temperature to $150 / 250{ }^{\circ} \mathrm{C}$ at $10{ }^{\circ} \mathrm{C} \mathrm{min}{ }^{-1}$ under a flow of nitrogen $(50 \mathrm{~mL}$ $\mathrm{min}^{-1}$ ) and cooled down to $0 /-50^{\circ} \mathrm{C}$ at $10^{\circ} \mathrm{C} \mathrm{min}^{-1}$, before they underwent two more heating/cooling cycles.

Thin films of $\mathbf{6 F}$ and $\mathbf{6 F}-\left[\mathrm{Co}_{2}(\mathrm{CO})_{6}\right]_{2}$ were prepared by dropcasting $250 \mu \mathrm{L}$ of a $20 \mathrm{mg} \mathrm{mL}^{-1}$ solution of each polymer in chlorobenzene onto a silicon wafer $\left(\right.$ area $\left.=1 \mathrm{~cm}^{2}\right)$. The samples were dried in air, transferred to a vacuum oven, and further dried at $60{ }^{\circ} \mathrm{C}$ for $16 \mathrm{~h}$ before they were heated at a rate of $10{ }^{\circ} \mathrm{C} \mathrm{min}-1$ to a temperature of $800{ }^{\circ} \mathrm{C}$ under a gentle flow of $\mathrm{N}_{2} / \mathrm{H}_{2}(95: 5)$ in a quartz tube within a Lindberg Blue $\mathrm{M}$ tube furnace. The temperature was maintained at $800{ }^{\circ} \mathrm{C}$ for an additional $3 \mathrm{~h}$ before the furnace was cooled to room temperature at a rate of $10{ }^{\circ} \mathrm{C} \min ^{-1}$. The samples were analyzed directly using scanning electron microscopy (SEM) at $1 \mathrm{keV}$ beam energy and elemental analysis was performed at $10 \mathrm{keV}$ beam energy on a LEO (Zeiss) 1540XB with an equipped Oxford X-sight X-ray detector and INCA analysis software at the Western Nanofabrication Facility.

\section{Electrochemical Methods}

Cyclic voltammetry experiments were performed with a Bioanalytical Systems Inc. (BASi) Epsilon potentiostat and analyzed using BASi Epsilon software. Typical electrochemical cells consisted of a three-electrode setup including a glassy carbon working electrode, platinum wire counter electrode, and silver wire pseudo reference electrode. Experiments were run at a scan rate of $100 \mathrm{mV} \mathrm{s}^{-1}$ in dry and degassed $\mathrm{CH}_{2} \mathrm{Cl}_{2}$ solutions of the analyte $(\sim 1 \mathrm{mM})$ and electrolyte (0.1 M $\left.\left[n \mathrm{Bu}_{4} \mathrm{~N}\right]\left[\mathrm{PF}_{6}\right]\right)$. Cyclic voltammograms were internally referenced against the ferrocene/ferrocenium redox couple ( $\sim 1 \mathrm{mM}$ internal standard) and corrected for internal cell resistance using the BASi Epsilon software. 
General synthetic procedure for copolymers $6 \mathrm{~F}, 6 \mathrm{~T}$, and $6 \mathrm{~B}$ Compound 5 ( $0.10 \mathrm{~g}, 0.15 \mathrm{mmol})$, dibromoaryl monomer $(0.15$ $\mathrm{mmol}), \mathrm{Pd}\left(\mathrm{PPh}_{3}\right)_{4}(0.004 \mathrm{~g}, 0.004 \mathrm{mmol}, 10 \%)$ and $\mathrm{CuI}(0.002$ $\mathrm{g}, 0.008 \mathrm{mmol}, 5 \%)$ were combined in a microwave vial. The solvent mixture, $3 \mathrm{~mL}$ DMF/DIPA/ $\mathrm{H}_{2} \mathrm{O}$ (2:1:0.03), was degassed by three freeze-pump-thaw cycles, brought into a glove box and added to the solids. The reaction vessel was sealed before it was heated to $100{ }^{\circ} \mathrm{C}$ for $60 \mathrm{~min}$ in a microwave reactor. The resulting dark green solution was diluted with $\mathrm{CH}_{2} \mathrm{Cl}_{2}(20 \mathrm{~mL})$, filtered and column chromatography was performed $\left(\mathrm{CH}_{2} \mathrm{Cl}_{2}, 20 \mathrm{~mL}\right.$ silica gel). The solvent was then removed and the resulting residue was dried overnight under vacuum. The solid was dissolved in ca. $2 \mathrm{~mL} \mathrm{CH}_{2} \mathrm{Cl}_{2}$ and precipitated into diethyl ether $(3 \times 100 \mathrm{~mL})$ and pentane $(2 \times$ $50 \mathrm{~mL}$ ), dried, dissolved in THF (ca. $5 \mathrm{~mL}$ ) and precipitated into methanol $(2 \times 50 \mathrm{~mL})$. The resulting dark green polymers were isolated by centrifugation and dried overnight under vacuum.

\section{Copolymer 6T}

From 2,5-dibromo-3-hexylthiophene (0.050 g, $0.15 \mathrm{mmol})$. Yield $=0.075 \mathrm{~g}, 60 \% .{ }^{1} \mathrm{H}$ NMR $\left(599.3 \mathrm{MHz}, \mathrm{CDCl}_{3}\right) \delta 8.23$ $(4 \mathrm{H}$, br s, aryl $\mathrm{CH}), 7.72-7.70(4 \mathrm{H}, \mathrm{m}$, aryl $\mathrm{CH}), 7.18(1 \mathrm{H}, \mathrm{s}$, thiophene- $\mathrm{CH}), 6.67-6.62(8 \mathrm{H}, \mathrm{m}$, aryl $\mathrm{CH}), 2.81-2.77(2 \mathrm{H}, \mathrm{t}$, $\left.J_{\mathrm{HH}}=8 \mathrm{~Hz}, \mathrm{CH}_{2}\right), 1.93\left(12 \mathrm{H}\right.$, br s, $\left.\mathrm{CH}_{3}\right), 1.74-1.69(2 \mathrm{H}, \mathrm{m}$, $\left.\mathrm{CH}_{2}\right), 1.40-1.29$ (6H, m, CH2), 0.93-0.89 (3H, m, CH3). FTIR (ATR): $v=2953$ (w sh), $2926(\mathrm{w}), 2854(\mathrm{w}) 1655(\mathrm{~m}$, $\mathrm{C}=\mathrm{O}), 1596$ (m), 1527 (s), 1488 (w), 1449 (w), 1429 (m), 1362 (s), $1217(\mathrm{~m}), 1168(\mathrm{~m}), 1053(\mathrm{w}), 1013(\mathrm{w}), 911(\mathrm{~m}), 852(\mathrm{~s})$, $743(\mathrm{~m}) \mathrm{cm}^{-1}$. UV-vis $\left(\mathrm{CH}_{2} \mathrm{Cl}_{2}\right): \lambda_{\max }(\varepsilon)=590 \mathrm{~nm}\left(5,700 \mathrm{M}^{-1}\right.$ $\left.\mathrm{cm}^{-1}\right), 387 \mathrm{~nm}\left(74,300 \mathrm{M}^{-1} \mathrm{~cm}^{-1}\right), 272 \mathrm{~nm}\left(45,900 \mathrm{M}^{-1} \mathrm{~cm}^{-1}\right)$. GPC (THF, conventional calibration): $\mathrm{M}_{\mathrm{n}}=6,575 \mathrm{~g} \mathrm{~mol}^{-1}, \mathrm{M}_{\mathrm{w}}$ $=18,250 \mathrm{~g} \mathrm{~mol}^{-1}, Ð=2.77$.

\section{Copolymer 6B}

From 1,4-dibromo-2,5-bis(hexyloxy)benzene (0.066 g, 0.15 mmol). Yield $=0.081 \mathrm{~g}, 57 \% .{ }^{1} \mathrm{H}$ NMR $\left(599.3 \mathrm{MHz}, \mathrm{CDCl}_{3}\right) \delta$ 8.22-8.15 (4H, m, aryl $\mathrm{CH}), 7.74-7.72(4 \mathrm{H}, \mathrm{m}$, aryl $\mathrm{CH}), 7.08$ $(2 \mathrm{H}$, s, aryl $\mathrm{CH}), 6.68-6.62(8 \mathrm{H}, \mathrm{m}$, aryl $\mathrm{CH}), 4.11-4.00(4 \mathrm{H}$, $\left.\mathrm{m}, \mathrm{OCH}_{2}\right), 1.94\left(12 \mathrm{H}\right.$, br. s, $\left.\mathrm{CH}_{3}\right), 1.91-1.88\left(4 \mathrm{H}, \mathrm{m}, \mathrm{CH}_{2}\right)$, 1.61-1.49 (4H, m, CH $H_{2}, 1.42-1.34\left(8 \mathrm{H}, \mathrm{m}, \mathrm{CH}_{2}\right), 0.96-0.89$ $\left(6 \mathrm{H}, \mathrm{m}, \mathrm{CH}_{3}\right)$. FT-IR (ATR): $v=3407(\mathrm{w}, \mathrm{C} \equiv \mathrm{C}), 2949$ (w sh), 2925 (w), 2856 (w) 1655 (m, C=O), 1596 (m), 1527 (s), 1429 (m), 1362 (s), 1217 (m), 1168 (m), 1053 (w), 1013 (w), 911 (m), $852(\mathrm{~s}), 743(\mathrm{~m}) \mathrm{cm}^{-1}$. UV-vis $\left(\mathrm{CH}_{2} \mathrm{Cl}_{2}\right): \lambda_{\max }(\varepsilon)=589 \mathrm{~nm}$ $\left(5,700 \mathrm{M}^{-1} \mathrm{~cm}^{-1}\right), 387 \mathrm{~nm}\left(57,400 \mathrm{M}^{-1} \mathrm{~cm}^{-1}\right), 330 \mathrm{~nm}(38,300$ $\left.\mathrm{M}^{-1} \mathrm{~cm}^{-1}\right), 302\left(\mathrm{sh}, 41,200 \mathrm{M}^{-1} \mathrm{~cm}^{-1}\right), 272\left(44,100 \mathrm{M}^{-1} \mathrm{~cm}^{-1}\right)$. GPC (THF, conventional calibration): $\mathrm{M}_{\mathrm{n}}=7,700 \mathrm{~g} \mathrm{~mol}^{-1}, \mathrm{M}_{\mathrm{w}}$ $=13,600 \mathrm{~g} \mathrm{~mol}^{-1}, Ð=1.76$.

\section{Synthesis of copolymer $6 \mathrm{~F}-\left[\mathrm{Co}_{2}(\mathrm{CO})_{6}\right]_{2}$}

In a glovebox, $6 \mathbf{F}(0.10 \mathrm{~g}, 0.10 \mathrm{mmol})$ was dissolved in $5 \mathrm{~mL}$ dry $\mathrm{CH}_{2} \mathrm{Cl}_{2}$. $\mathrm{Co}_{2}(\mathrm{CO}) 8(0.09 \mathrm{~g}, 0.25 \mathrm{mmol})$ was then added to the solution, causing the immediate evolution of gas. The reaction mixture was stirred at room temperature for $30 \mathrm{~min}$. Once the reaction was complete, column chromatography was performed $\left(\mathrm{CH}_{2} \mathrm{Cl}_{2}, 20 \mathrm{~mL}\right.$ silica gel). The solvent was removed under reduced pressure, and the residue was dissolved in ca. $1 \mathrm{~mL}$ of $\mathrm{CH}_{2} \mathrm{Cl}_{2}$ and precipitated into pentane $(1 \times 50$ $\mathrm{mL}$, then $2 \times 30 \mathrm{~mL}$ ). The solvent was then decanted and the dark green solid was dried overnight under vacuum to give $\mathbf{6 F}$ $\left[\mathrm{Co}_{2}(\mathbf{C O})_{6}\right]_{2}$ as a dark green/brown powder. Yield $=0.15 \mathrm{~g}$, 95\%. ${ }^{1} \mathrm{H}$ NMR $\left(599.3 \mathrm{MHz}, \mathrm{CDCl}_{3}\right) \delta 8.30-8.24$ (4H, m, aryl $\mathrm{CH}), 7.84-7.49(10 \mathrm{H}, \mathrm{m}$, aryl $\mathrm{CH}), 6.70(4 \mathrm{H}$, br. s, aryl $\mathrm{CH})$, $6.62(4 \mathrm{H}$, br. s, aryl $\mathrm{CH}), 2.00\left(12 \mathrm{H}, \mathrm{s}, \mathrm{CH}_{3}\right), 1.94\left(4 \mathrm{H}, \mathrm{s}, \mathrm{CH}_{2}\right)$, 1.33-1.08 (12H, m, CH2), 0.90-0.71 (10H, m, CH2, CH3). FTIR (ATR): $v=2957$ (m), 2920 (m), 2853 (m) 2088 (s, C=O), 2051 (s, C=O), 2019 (s, C=O), 1725 (w), 1658 (w, C=O), 1596 (w), $1551(\mathrm{~m}), 1454(\mathrm{w}), 1377$ (s), 1223 (m), 1055 (m), 910 (m), $799(\mathrm{~m}), 744(\mathrm{~m}) \mathrm{cm}^{-1}$. UV-vis $\left(\mathrm{CH}_{2} \mathrm{Cl}_{2}\right): \lambda_{\max }(\varepsilon)=587$ $\mathrm{nm}\left(9,900 \mathrm{M}^{-1} \mathrm{~cm}^{-1}\right), 385 \mathrm{~nm}\left(71,500 \mathrm{M}^{-1} \mathrm{~cm}^{-1}\right), 270(85,900$ $\mathrm{M}^{-1} \mathrm{~cm}^{-1}$ ). GPC (THF, conventional calibration): $\mathrm{M}_{\mathrm{n}}=7,700$ $\mathrm{g} \mathrm{mol}^{-1}, \mathrm{M}_{\mathrm{w}}=10,900 \mathrm{~g} \mathrm{~mol}^{-1}$, and $Ð=1.41$.

\section{Synthesis of complex 8}

A Schlenk flask equipped with a stir bar was charged with

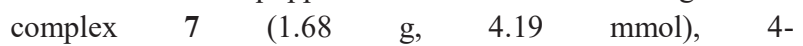
[(trimethylsilyl)ethynyl]benzoyl chloride $(1.00 \mathrm{~g}, 4.19 \mathrm{mmol})$ and dry toluene $(100 \mathrm{~mL})$ in a glove box. Upon removal, dry and degassed triethylamine $(4.67 \mathrm{~mL}, 33.5 \mathrm{mmol})$ was added and the vessel was fitted with a condenser and heated to 125 ${ }^{\circ} \mathrm{C}$. After stirring for $16 \mathrm{~h}$, the mixture was cooled to room temperature and filtered in vacuo. The solvent was then removed. Column chromatography $\left(\mathrm{CH}_{2} \mathrm{Cl}_{2} / \mathrm{Hexanes}\right.$, 2:1, 100 $\mathrm{mL}$ silica gel) was performed to yield complex $\mathbf{8}$ as a dark green solid. Yield $=0.57 \mathrm{~g}, 23 \%$ yield (and 9; $1.26 \mathrm{~g}, 38 \%$. The characterization data for complex 9 were reported elsewhere). ${ }^{59}$ ${ }^{1} \mathrm{H}$ NMR (400.1 MHz, $\left.\mathrm{CDCl}_{3}\right): \delta 8.15\left(\mathrm{~d}, 2 \mathrm{H}, J_{\mathrm{HH}}=8 \mathrm{~Hz}\right.$, aryl $\mathrm{CH}), 7.61\left(\mathrm{~d}, 2 \mathrm{H}, J_{\mathrm{HH}}=8 \mathrm{~Hz}\right.$, aryl $\left.\mathrm{CH}\right), 6.72\left(\mathrm{dd}, 2 \mathrm{H}, J_{\mathrm{HH}}=8\right.$, $1 \mathrm{~Hz}$, aryl CH) 6.62-6.60 (m, 4H, aryl CH), 6.57-6.55 (m, 2H, aryl $\mathrm{CH}), 4.86(\mathrm{~s}, 1 \mathrm{H}, \mathrm{CH}), 2.10(\mathrm{~s}, 6 \mathrm{H}, \mathrm{CH}), 1.88(\mathrm{~s}, 6 \mathrm{H}$, $\left.\mathrm{CH}_{3}\right), 0.28\left(\mathrm{~s}, 9 \mathrm{H}, \mathrm{SiCH}_{3}\right),{ }^{13} \mathrm{C} \mathrm{NMR}\left(100.6 \mathrm{MHz}_{2} \mathrm{CDCl}_{3}\right) \delta$ 199.5, 155.4, 153.8, 147.4, 147.2, 138.6, 132.4, 129.5, 128.1, $122.9,121.8,121.7,120.9,120.5,111.3,104.2,98.3,21.9$, 20.7, -0.2. FT-IR (ATR): $v=2957(\mathrm{w}, \mathrm{CH}), 2158(\mathrm{w}, \mathrm{C} \equiv \mathrm{C})$, 1638 (m, C=O), 1596 (m), 1529 (s), 1453 (m), 1430 (m), 1381 (s), $1168(\mathrm{~m}), 1215$ (s), 1168 (m), 913 (m), 840 (m), 743 (m) $\mathrm{cm}^{-1}$. UV-vis $\left(\mathrm{CH}_{2} \mathrm{Cl}_{2}\right): \lambda_{\max }(\varepsilon) 589 \mathrm{~nm}\left(5,500 \mathrm{M}^{-1} \mathrm{~cm}^{-1}\right), 433$ $\mathrm{nm}\left(\mathrm{sh}, 14,100 \mathrm{M}^{-1} \mathrm{~cm}^{-1}\right), 392 \mathrm{~nm}\left(33,400 \mathrm{M}^{-1} \mathrm{~cm}^{-1}\right), 301 \mathrm{~nm}$ (sh, 52,800, $\left.\mathrm{M}^{-1} \mathrm{~cm}^{-1}\right), 285 \mathrm{~nm}\left(60,800 \mathrm{M}^{-1} \mathrm{~cm}^{-1}\right)$. Mass Spec. (ESI, +ve mode) $m / z:[\mathrm{M}]^{+}$calc'd for $\left[\mathrm{C}_{34} \mathrm{H}_{34} \mathrm{~N}_{4} \mathrm{NiOSi}\right]^{+}$, 600.1855; found, 600.1853; difference: $-0.3 \mathrm{ppm}$.

\section{Synthesis of complex 10}

Complex 8 (0.20 g, $0.33 \mathrm{mmol})$ was stirred with $\mathrm{K}_{2} \mathrm{CO}_{3}(0.09$ $\mathrm{g}, 0.67 \mathrm{mmol})$ in THF/MeOH $(3: 1,16 \mathrm{~mL})$ for $16 \mathrm{~h} . \mathrm{CH}_{2} \mathrm{Cl}_{2}$ was added and the organic layer was washed with $0.5 \mathrm{M}$ 
aqueous $\mathrm{NH}_{4} \mathrm{Cl}(50 \mathrm{~mL})$, dried with $\mathrm{MgSO}_{4}$ and concentrated in vacuo. The resulting dark green solid was purified via precipitation from a saturated $\mathrm{CH}_{2} \mathrm{Cl}_{2}$ solution in pentane to afford $\mathbf{1 0}$ as a dark green microcrystalline solid. Yield $=0.14$ g, 81\%. ${ }^{1} \mathrm{H}$ NMR (400.1 MHz, $\left.\mathrm{CDCl}_{3}\right): \delta 8.18\left(\mathrm{~d}, 2 \mathrm{H}, J_{\mathrm{HH}}=7\right.$ $\mathrm{Hz}$, aryl $\mathrm{CH}), 7.65\left(\mathrm{~d}, 2 \mathrm{H}, J_{\mathrm{HH}}=8 \mathrm{~Hz}\right.$, aryl $\left.\mathrm{CH}\right), 6.73(\mathrm{~d}, 2 \mathrm{H}$, $\left.J_{\mathrm{HH}}=8 \mathrm{~Hz}\right) 6.62-6.60(\mathrm{~m}, 4 \mathrm{H}$, aryl $\mathrm{CH}), 6.57-6.56(\mathrm{~m}, 2 \mathrm{H}$, aryl $\mathrm{CH}) 4.87(\mathrm{~s}, 1 \mathrm{H}, \mathrm{CH}), 3.28(\mathrm{~s}, 1 \mathrm{H}, \mathrm{C} \equiv \mathrm{C}-H), 2.10(\mathrm{~s}, 6 \mathrm{H}$, $\left.\mathrm{CH}_{3}\right), 1.90\left(\mathrm{~s}, 6 \mathrm{H}, \mathrm{CH}_{3}\right) .{ }^{13} \mathrm{C} \mathrm{NMR}\left(100.6 \mathrm{MHz}, \mathrm{CDCl}_{3}\right) \delta$ 199.4, 155.4, 153.8, 147.4, 147.1, 139.0, 132.6, 129.5, 127.0, 123.0, 121.8, 121.7, 120.9, 120.4, 111.2, 82.9, 80.5, 21.9, 20.7. FT-IR (ATR): $v=3301(\mathrm{w}), 1663(\mathrm{w}, \mathrm{C}=\mathrm{O}), 1597(\mathrm{w}), 1530$ (m), 1454 (m), 1429 (m), 1382 (s), 1365 (s), 1217 (m), 1166 (m), 1054 (m), 913 (m), 853 (s), 772 (m), 746 (s), 645 (m), 617 (m) $\mathrm{cm}^{-1}$. UV-vis $\left(\mathrm{CH}_{2} \mathrm{Cl}_{2}\right): \lambda_{\max }(\varepsilon) 588 \mathrm{~nm}\left(4,100 \mathrm{M}^{-1} \mathrm{~cm}^{-1}\right)$,

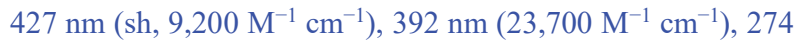
$\mathrm{nm}\left(33,700 \mathrm{M}^{-1} \mathrm{~cm}^{-1}\right)$. Mass Spec. (ESI, +ve mode) $\mathrm{m} / \mathrm{z}$ : [M] ${ }^{+}$ calc'd for $\left[\mathrm{C}_{31} \mathrm{H}_{26} \mathrm{~N}_{4} \mathrm{NiO}\right]^{+}, 528.1460$; found, 528.1452; difference: $-1.5 \mathrm{ppm}$.

\section{Synthesis of model compound 11}

Compound 10 (0.11 g, $0.21 \mathrm{mmol})$, 2,7-dibromo-9,9dihexylfluorene (0.05 g, $0.10 \mathrm{mmol}), \mathrm{Pd}\left(\mathrm{PPh}_{3}\right)_{4}(0.006 \mathrm{~g}, 0.005$ $\mathrm{mmol})$ and $\mathrm{CuI}(2.0 \mathrm{~g}, 0.011 \mathrm{mmol})$ were combined in a $5 \mathrm{~mL}$ microwave vial. The solvent mixture, $3 \mathrm{~mL}$ DMF/DIPA/ $\mathrm{H}_{2} \mathrm{O}$ (2:1:0.03) was degassed by 3 freeze-pump-thaw cycles, brought into a glove box and added to the solid. The microwave vial was sealed and then heated at $100{ }^{\circ} \mathrm{C}$ for $45 \mathrm{~min}$ in a microwave reactor. Upon cooling, $\mathrm{CH}_{2} \mathrm{Cl}_{2}(10 \mathrm{~mL})$ was added to the dark green solution and the entire mixture washed with $\mathrm{H}_{2} \mathrm{O}(6 \times 100 \mathrm{~mL})$, dried with $\mathrm{MgSO}_{4}$ and concentrated in vacuo. The resulting dark green residue was purified using a column chromatography $\left(\mathrm{CH}_{2} \mathrm{Cl}_{2}, 25 \mathrm{~mL}\right.$ silica gel) to afford $\mathbf{1 1}$ as a dark green microcrystalline solid after solvent removal in vacuo. Yield $=0.12 \mathrm{~g}, 83 \% .{ }^{1} \mathrm{H} \mathrm{NMR}\left(599.4 \mathrm{MHz}, \mathrm{CDCl}_{3}\right)$ : $\delta 8.23\left(\mathrm{~d}, 4 \mathrm{H},{ }^{3} \mathrm{~J}_{\mathrm{HH}}=8 \mathrm{~Hz}\right.$, aryl $\left.\mathrm{CH}\right), 7.72(\mathrm{~m}, 6 \mathrm{H}$, aryl $\mathrm{CH})$, 7.59-7.54 (m, 2H, aryl CH), $7.56(\mathrm{~s}, 2 \mathrm{H}$, aryl $\mathrm{CH}), 6.74(\mathrm{~m}, 4 \mathrm{H}$, aryl $\mathrm{CH}), 6.67-6.61(\mathrm{~m}, 8 \mathrm{H}$, aryl $\mathrm{CH}), 6.58-6.56(\mathrm{~m}, 4 \mathrm{H}$, aryl $\mathrm{CH}), 4.89$ (s, 2H, CH), $2.12\left(\mathrm{~s}, 12 \mathrm{H}, \mathrm{CH}_{3}\right) 2.04-2.01(\mathrm{~m}, 4 \mathrm{H}$, $\left.\mathrm{CH}_{2}\right), 1.94\left(\mathrm{~s}, 12 \mathrm{H}, \mathrm{CH}_{3}\right), 1.16-1.05\left(\mathrm{~m}, 12 \mathrm{H}, \mathrm{CH}_{2}\right), 0.78$ (t, $\left.6 \mathrm{H},{ }^{3} \mathrm{~J}_{\mathrm{HH}}=8 \mathrm{~Hz}, \mathrm{CH}_{3}\right), 0.68-0.63\left(\mathrm{~m}, 4 \mathrm{H}, \mathrm{CH}_{2}\right) .{ }^{13} \mathrm{C} \mathrm{NMR}$ $\left(150.7 \mathrm{MHz}, \mathrm{CDCl}_{3}\right): \delta 199.5,155.4,153.9,151.3,147.4$,
$147.2,141.1,138.4,132.0,131.0,129.7,128.5,126.1,122.9$, $121.9,121.8,121.5,120.9,120.6,120.2,111.3,94.0,89.3$, 55.4, 40.4, 31.5, 29.7, 23.7, 22.6, 21.9, 20.7, 14.0. FT-IR (ATR): $v=2952(\mathrm{~s}$, hex CH), $2923(\mathrm{~s}$, hex CH), 2852 (s, hex $\mathrm{CH}), 1631$ (m, C=O), 1595 (m), 1527 (s), 1454 (m), 1430 (m), 1381 (s), 1215 (m), 1051 (m), 1022 (m), 912 (m), 853 (m), 819 (m), $742(\mathrm{~m}) \mathrm{cm}^{-1}$. UV-vis $\left(\mathrm{CH}_{2} \mathrm{Cl}_{2}\right): \lambda_{\max }(\varepsilon)=584 \mathrm{~nm}(7,900$ $\left.\mathrm{M}^{-1} \mathrm{~cm}^{-1}\right), 387 \mathrm{~nm}\left(91,100 \mathrm{M}^{-1} \mathrm{~cm}^{-1}\right), 273 \mathrm{~nm}\left(52,100 \mathrm{M}^{-1}\right.$ $\mathrm{cm}^{-1}$ ). Mass Spec. (ESI, +ve mode) $\mathrm{m} / \mathrm{z}:[\mathrm{M}+\mathrm{H}]^{+}$calc'd for $\left[\mathrm{C}_{87} \mathrm{H}_{83} \mathrm{~N}_{8} \mathrm{Ni}_{2} \mathrm{O}_{2}\right]^{+}$, 1387.5346; found, 1387.5365; difference: +1.4 ppm.

\section{RESULTS AND DISCUSSION}

\section{Copolymer Synthesis}

Polymers (6F, 6T, and 6B) containing 9,9-dihexylfluorene (F), 3-hexylthiophene (T), or 2,5-bis(hexyloxy)benzene (B) and a $\mathrm{Ni}(\mathrm{II})$ complex of Goedken's macrocycle (5) were synthesized using previously optimized polymerization conditions (Scheme 1). ${ }^{59}$ These comonomers were chosen for polymerization due to their $\pi$-conjugated nature and ability to potentially solubilize the rigid, $\pi$-conjugated backbones of the targeted copolymers (Scheme 1). The monomers were combined in equimolar quantities and dissolved in a dimethylformamide (DMF), diisopropylamine (DIPA), and water mixture (2:1:0.03). Sonogashira cross-coupling polymerization was performed using a catalytic amount of tetrakis(triphenylphosphine) palladium $(2.5 \%)$ and copper iodide $(5.0 \%)$ submitted to microwave irradiation for $60 \mathrm{~min}$ at $100{ }^{\circ} \mathrm{C}$. Purification of the polymers involved column chromatography to remove catalyst, removal of the majority of DMF and DIPA in vacuo and precipitation in diethyl ether from $\mathrm{CH}_{2} \mathrm{Cl}_{2}$, in pentane from $\mathrm{CH}_{2} \mathrm{Cl}_{2}(2 \times 50 \mathrm{~mL})$, and in $\mathrm{MeOH}(2 \times 50 \mathrm{~mL})$ from THF, in order to remove shorter molecular weight oligomers as well as residual DIPA and DMF. The isolated yields for copolymers 6F, 6T, and 6B were 59, 60, and 57\% respectively, and a summary of the molecular weight data acquired by gel permeation chromatography (GPC) can be found in Table 1. The relatively low molecular weights and broad molecular weight distributions observed are consistent with the stepgrowth polymerization method employed. Additional details,

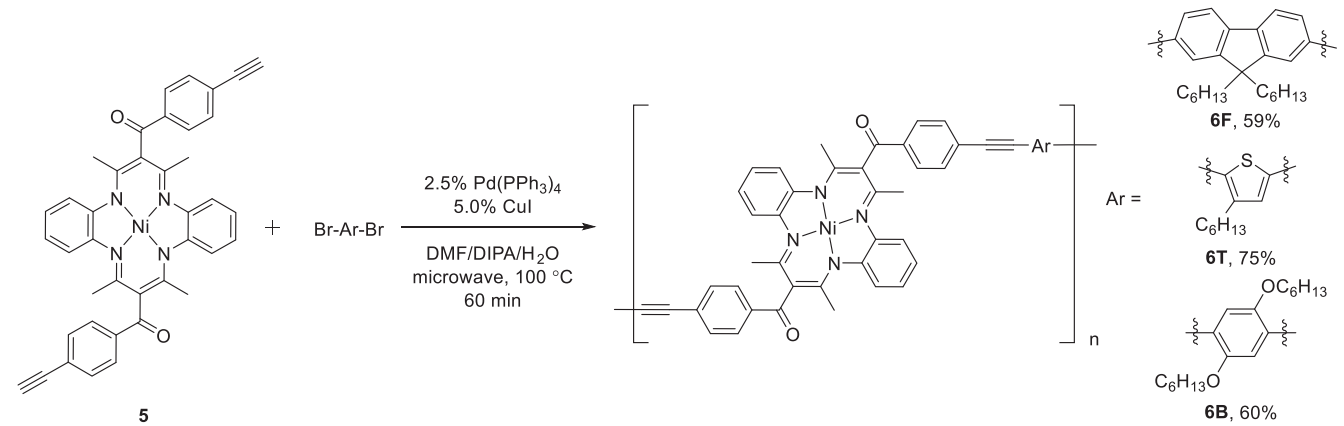

SCHEME 1 Synthesis of copolymers $6 \mathrm{~F}, 6 \mathrm{~B}$, and $6 \mathrm{~T}$. 
TABLE 1 Summary of GPC data for copolymers $6 \mathrm{~F}, 6 \mathrm{~F}-\left[\mathrm{CO}_{2}(\mathrm{CO})_{6}\right]_{2}$, $6 \mathrm{~B}$, and $6 \mathrm{~T}$.

\begin{tabular}{llll}
\hline Compound & $\mathrm{M}_{\mathrm{n}}\left(\mathrm{g} \mathrm{mol}^{-1}\right)$ & $\mathrm{M}_{\mathrm{w}}\left(\mathrm{g} \mathrm{mol}^{-1}\right)$ & $\oplus$ \\
6F & 7,825 & 11,800 & 1.51 \\
6F-[Co2$\left.(\mathrm{CO})_{6}\right]_{2}$ & 7,700 & 10,900 & 1.41 \\
6T & 6,575 & 18,250 & 2.77 \\
6B & 7,700 & 13,600 & 1.76
\end{tabular}

including thermal analysis and spectroscopic data are discussed below (Figures S1, S2).

\section{Model Compound Synthesis}

In order to gain further insight into the spectroscopic properties of the copolymers, specifically $\mathbf{6 F}$, model compounds $\mathbf{1 1}$ and 12 were prepared via similar Sonogashira cross-coupling reactions (Scheme 2). The first model compound consisted of two Ni(II) complexes of Goedken's macrocycles bridged by a 9,9-dihexylfluorene molecule (11). The second model compound consisted of two 9,9-dihexylfluorene molecules bridged by a single Ni(II) complex of Goedken's macrocycle (12). To synthesize compound $\mathbf{1 1}$, access to a Ni(II) complex of Goedken's macrocycle substituted with a single alkyne functionality was required. Thus, a mixture of 4[(trimethylsilyl)ethynyl]-benzoyl chloride and compound 7 was heated to reflux in the presence of triethylamine (Scheme $2)$. This reaction afforded a mixture of mono- (8) and disubstituted (9) macrocycles which could be separated using column chromatography, in 23 and $38 \%$ yield, respectively. The identity of complex $\mathbf{8}$ was confirmed by NMR spectroscopy (Figures S3, S4). Removal of the TMS group from compounds 8 and $\mathbf{9}$ was achieved using potassium carbonate to afford compounds $\mathbf{1 0}$ and $\mathbf{5}$ in 81 and $90 \%$ yield, respectively (Figures S5, S6).

Microwave irradiation of a mixture of two equiv. of $\mathbf{1 0}$ with one equiv. of 2,7-dibromo-9,9-dihexylfluorene for $30 \mathrm{~min}$ at
TABLE 2 UV-vis absorption spectroscopy data for copolymers 6F, $6 \mathrm{~F}-\left[\mathrm{Co}_{2}(\mathrm{CO})_{6}\right]_{2}, 6 \mathrm{~T}$, and $6 \mathrm{~B}$, and model compounds 11 and 12 in $\mathrm{CH}_{2} \mathrm{Cl}_{2}$.

\begin{tabular}{|c|c|c|c|}
\hline \multirow[b]{2}{*}{ Compound } & \multicolumn{3}{|c|}{$\lambda_{\max }(\mathrm{nm}), \varepsilon\left(\mathrm{M}^{-1} \mathrm{~cm}^{-1}\right)$} \\
\hline & $\pi \rightarrow \pi^{*}{ }_{1}$ & $\pi \rightarrow \pi^{*} 2$ & LMCT $^{\mathrm{a}}$ \\
\hline $6 F^{59}$ & $275,50,900$ & $378,100,800$ & $588,6,000$ \\
\hline $6 \mathrm{~F}-\left[\mathrm{Co}_{2}(\mathrm{CO})_{6}\right]_{2}$ & $270,85,900$ & $385,71,500$ & $587,9,900$ \\
\hline 6T & $272,45,900$ & $387,74,300$ & $590,5,700$ \\
\hline $6 B$ & $272,44,100$ & $387,57,400$ & $589,5,700$ \\
\hline 11 & $273,52,100$ & $387,91,100$ & $584,7,900$ \\
\hline $12^{59}$ & $283,67,600$ & $349,109,200$ & $587,7,100$ \\
\hline
\end{tabular}

$100{ }^{\circ} \mathrm{C}$ in the presence of $\mathrm{Pd}\left(\mathrm{PPh}_{3}\right)_{4}$ and $\mathrm{CuI}$ dissolved in DMF/DIPA/ $\mathrm{H}_{2} \mathrm{O}$ (2:1:0.03) produced compound $\mathbf{1 1}$ in $83 \%$ yield after purification by column chromatography (Figures S7, S8).

\section{UV-vis Absorption Spectroscopy}

The UV-vis absorption spectra of polymers $6 \mathbf{F}, \mathbf{6 T}$, and $6 \mathbf{B}$ are presented in Figure 1a and the spectral features summarized in Table 2 . The spectra of polymers $\mathbf{6 T}$ and $\mathbf{6 B}$ showed absorption maxima at $272 \mathrm{~nm}\left(\mathbf{6 T}, \varepsilon=45,900\right.$ and $\mathbf{6 B}, \varepsilon=44,100 \mathrm{M}^{-1}$ $\left.\mathrm{cm}^{-1}\right), 387 \mathrm{~nm}\left(6 \mathbf{T}, \varepsilon=74,300\right.$ and $\left.\mathbf{6 B}, \varepsilon=57,400 \mathrm{M}^{-1} \mathrm{~cm}^{-1}\right)$ and similar low-energy absorption maxima at $c a .590 \mathrm{~nm}$ $\left(5,700 \mathrm{M}^{-1} \mathrm{~cm}^{-1}\right)$. Similarly, polymer $\mathbf{6 F}$ yielded absorption maxima at $275 \mathrm{~nm}\left(50,900 \mathrm{M}^{-1} \mathrm{~cm}^{-1}\right), 378 \mathrm{~nm}\left(100,800 \mathrm{M}^{-1}\right.$ $\left.\mathrm{cm}^{-1}\right)$, and $588 \mathrm{~nm}\left(6,000 \mathrm{M}^{-1} \mathrm{~cm}^{-1}\right)$. The low energy absorption has been previously assigned in molecular analogues to a charge transfer from the highest ligand occupied molecular orbital of the macrocyclic backbone to the lowest empty d orbital of $\mathrm{Ni}(\mathrm{II}){ }^{66}$ It was observed that the absorption at $c a .590 \mathrm{~nm}$ remains essentially unchanged in the copolymers due to the lack of long range electronic delocalization via the orthogonal arrangement of the $\mathrm{Ni}$ (II) macrocycle units and the organic spacers, as previously inferred by the solid-state

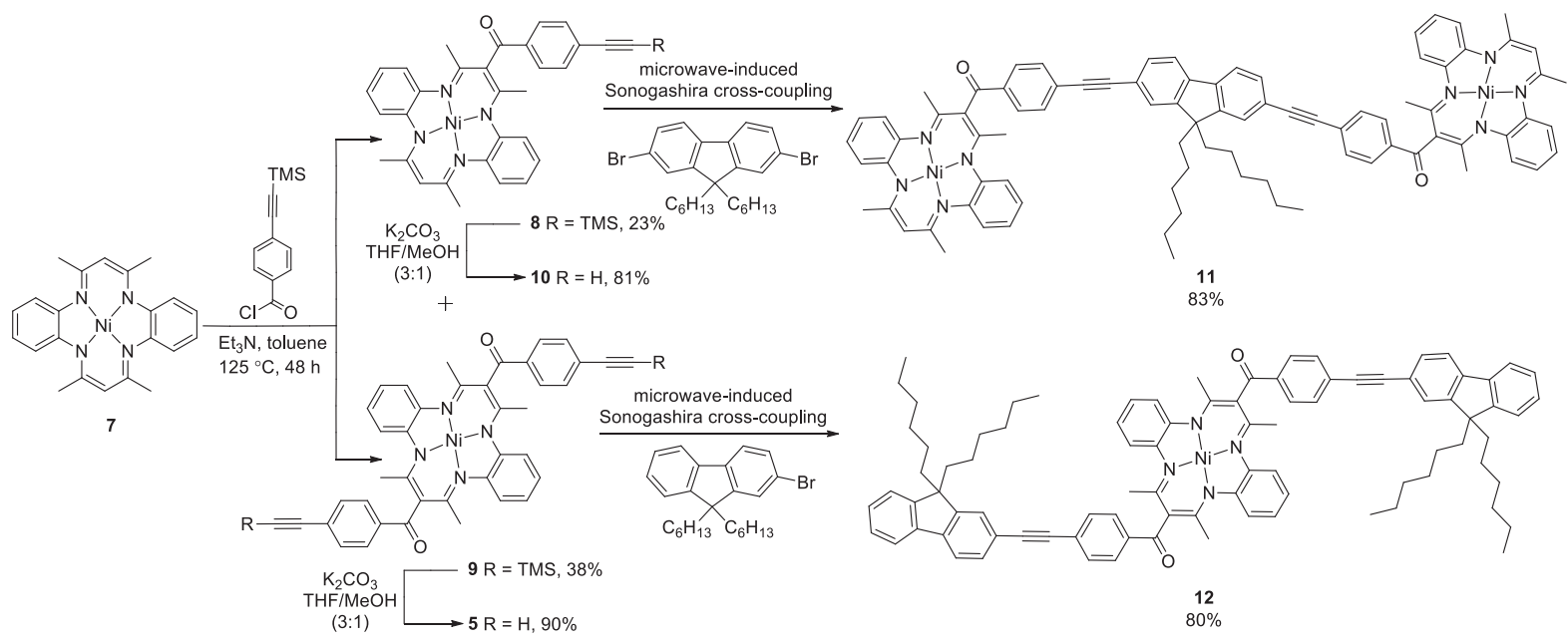

SCHEME 2 Synthesis of model compounds 11 and 12. 

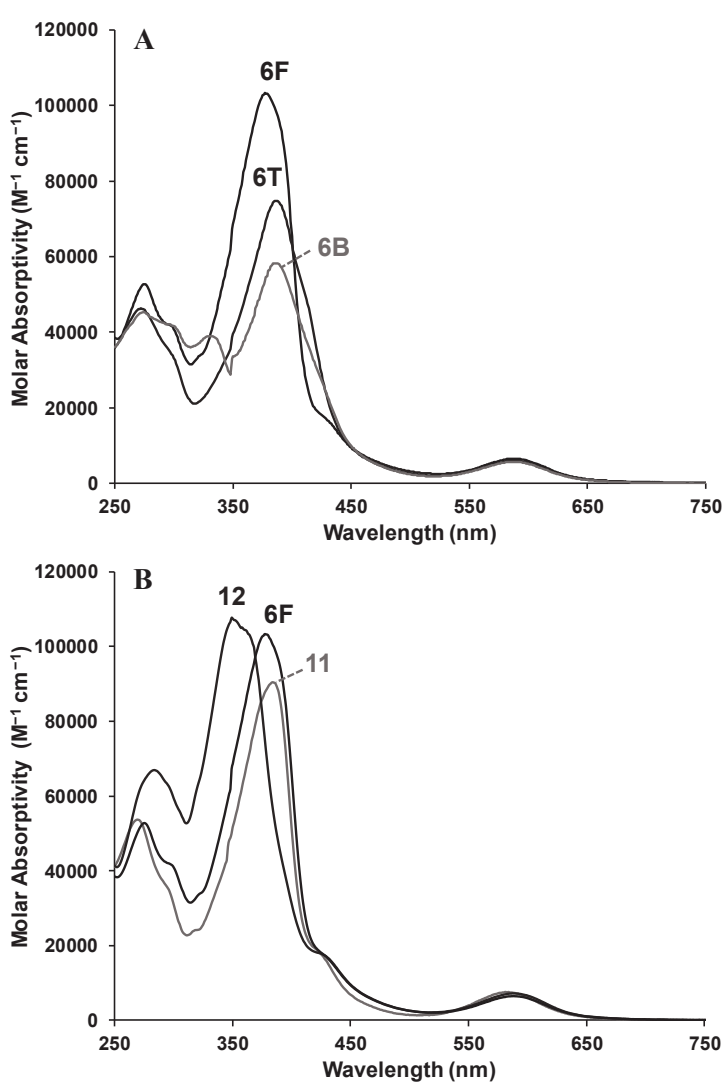

FIGURE 1 UV-vis absorption spectra recorded in $\mathrm{CH}_{2} \mathrm{Cl}_{2}$. A) Comparison of copolymers 6F, 6T, and 6B. B) Comparison of model compounds 11,12 , and copolymer $6 \mathrm{~F}$.

structure of $5 .^{59}$ The high-energy absorptions at $c a .272 \mathrm{~nm}$ is thought to be a $\pi \rightarrow \pi^{*}$ transition associated with Goedken's macrocycle, while the transition at $c a .387 \mathrm{~nm}$ appears to originate primarily from a macrocycle centered $\pi \rightarrow \pi^{*}$ transition associated with the $\pi$-conjugated organic spacer in each structure. The $\pi \rightarrow \pi_{2}{ }_{2}$ transition of copolymer $6 \mathbf{F}$ is blueshifted by ca. $10 \mathrm{~nm}$ compared to these of copolymers 6 $\mathbf{T}$ and 6B. This trend is consistent with that observed for the wavelengths of maximum absorption of poly(9,9dihexylfluorene) and poly(3-hexylthiophene) and may relate to the antiaromatic nature of the 9,9-dihexylfluorene spacer. ${ }^{67-68}$

In order to further understand the absorption properties of the copolymers, the absorption behavior of model complexes $\mathbf{1 1}$ and 12 were examined. Model compound 11, which contains two Ni(II) complexes bridged by a 9,9-dihexylfluorene, shows absorption maxima at 584, 387, and $273 \mathrm{~nm}$ (Figure 1b). Model compound 12, which contains two fluorene molecules and one Ni(II) complex, shows absorbance maxima at 587, 349, and $283 \mathrm{~nm}$. The intermediate absorption maxima at $349 \mathrm{~nm}$ was blue-shifted with respect to $\mathbf{6 F}$ and $\mathbf{1 1}$, which both had maximum absorptions at $387 \mathrm{~nm}$. This is thought to be due to the presence of a shorter conjugated $\pi$-system [CO-Ph-alkyne(9,9-dihexylfluorene)] within the backbone in compound $\mathbf{1 2}$, compared to the relatively large CO-Ph-alkyne-(9,9dihexylfluorene)-alkyne-Ph-CO system present in model compound $\mathbf{1 1}$ and copolymer $\mathbf{6 F}$. The increase in $\pi$-conjugation accounts for ten additional $\pi$-electrons and results in a red-shift in $\lambda_{\max }$ of $38 \mathrm{~nm}$. The $\mathrm{Ni}(\mathrm{II})$ based absorption at $c a .590 \mathrm{~nm}$ for $\mathbf{1 1}, \mathbf{1 2}$, and $\mathbf{6 F}$ were unchanged regardless of the degree of $\pi$ conjugation within the organic spacer (Table 2).

\section{Cyclic Voltammetry}

The electrochemical properties of polymers $6 \mathrm{~F}, 6 \mathrm{~T}$, and $6 \mathrm{~B}$ are summarized in Table 3. Cyclic voltammetry studies of the copolymers revealed two reversible one-electron oxidation events at $\mathrm{E}^{\circ}{ }_{\text {ox } 1}=0.24$ and $\mathrm{E}^{\circ}{ }_{\text {ox } 2}=0.74 \mathrm{~V}$ for $6 \mathbf{F}, \mathrm{E}^{\circ}{ }_{\text {ox } 1}=0.23$ and $\mathrm{E}^{\circ}{ }_{\text {ox } 2}=0.74 \mathrm{~V}$ for $6 \mathrm{~T}$, and $\mathrm{E}^{\circ}{ }_{\text {ox } 1}=0.25$ and $\mathrm{E}^{\circ}{ }_{\text {ox } 2}=0.75 \mathrm{~V}$ for $6 \mathbf{B}$ in $\mathrm{CH}_{2} \mathrm{Cl}_{2}$, relative to the ferrocene/ferrocenium redox couple (Figure 2). Model compound $\mathbf{1 2}$ also produced two reversible one-electron oxidation waves at $\mathrm{E}^{\circ}{ }_{\text {oxl }}=0.25$ and $\mathrm{E}^{\circ}{ }_{\mathrm{ox2}}=0.76 \mathrm{~V}$ (Figure S9). The electrochemical behavior of model compound $\mathbf{1 1}$ was considerably more complicated, although similar to other unsubstituted $\mathrm{Ni}(\mathrm{II})$ complexes of Goedken's macrocycle (Figure S10). ${ }^{66}$ Compound $\mathbf{1 1}$ gave rise to three irreversible oxidation waves at $\mathrm{E}_{\mathrm{pa}(1)}=0.16 \mathrm{~V}, \mathrm{E}_{\mathrm{pa}(2)}=$ $0.92 \mathrm{~V}$, and $\mathrm{E}_{\mathrm{pa}(3)}=1.11 \mathrm{~V}$ and a single irreversible reduction

TABLE 3 Cyclic voltammetry data for polymers $6 \mathrm{~F}, 6 \mathrm{~T}, 6 \mathrm{~B}$ and model

\begin{tabular}{ccccccc}
\multicolumn{2}{c}{ compounds 11 and 12. } & & & & \\
\hline Compounds & $\mathrm{E}_{\mathrm{pa}(1)^{\mathrm{b}}}$ & $\mathrm{E}_{\mathrm{ox} 1}^{\circ}$ & $\mathrm{E}_{\mathrm{pc}(1)^{\mathrm{c}}}$ & $\mathrm{E}_{\mathrm{ox} 2}^{\circ}$ & $\mathrm{E}_{\mathrm{pa}(2)^{\mathrm{b}}}$ & $\mathrm{E}_{\mathrm{pa}(3)^{\mathrm{b}}}$ \\
$6 \mathrm{~F}^{59}$ & - & 0.24 & - & 0.74 & - & - \\
$6 \mathrm{~T}$ & - & 0.23 & - & 0.74 & - & - \\
$6 \mathrm{~B}$ & - & 0.25 & - & 0.75 & - & - \\
11 & 0.16 & - & 0.74 & - & 0.92 & 1.11 \\
$12^{59}$ & - & 0.25 & - & 0.76 & - & -
\end{tabular}

${ }^{\text {a }}$ Recorded at a scan rate of $100 \mathrm{mV} \mathrm{s}^{-1}$ in a $\mathrm{CH}_{2} \mathrm{Cl}_{2}$ solution containing $1 \times 10^{-3}$ $\mathrm{M}$ analyte and $0.1 \mathrm{M}\left[n \mathrm{Bu}_{4} \mathrm{~N}\right]\left[\mathrm{PF}_{6}\right]$ as supporting electrolyte. Potentials reported in $\mathrm{V}$ relative to the ferrocene/ferrocenium redox couple.

${ }^{\mathrm{b}}$ Irreversible process, anodic peak potential $\left(\mathrm{E}_{\mathrm{pa}}\right)$ reported.

${ }^{\mathrm{c}}$ Irreversible process, cathodic peak potential $\left(\mathrm{E}_{\mathrm{pc}}\right)$ reported.

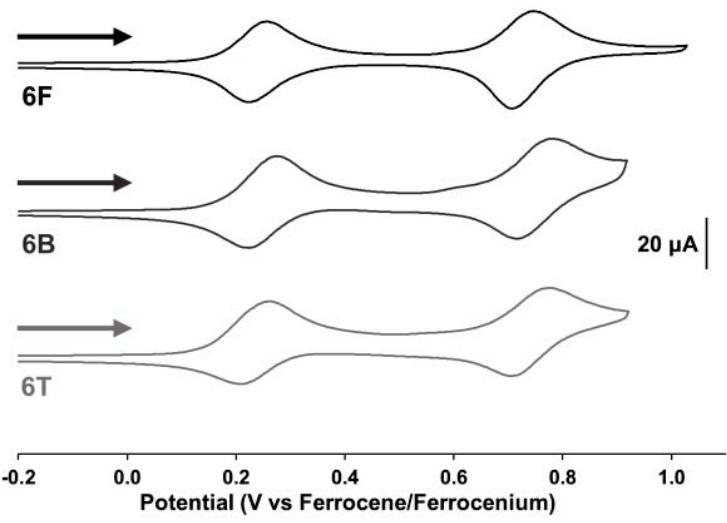

FIGURE 2 Cyclic voltammagrams of $6 \mathrm{~F}, 6 \mathrm{~T}$, and $6 \mathrm{~B}$ recorded at a scan rate of $100 \mathrm{mV} \mathrm{s}^{-1}$ in $\mathrm{CH}_{2} \mathrm{Cl}_{2}$ solutions containing $1 \times 10^{-3} \mathrm{M}$ analyte and $0.1 \mathrm{M}\left[n \mathrm{Bu}_{4} \mathrm{~N}\right]\left[\mathrm{PF}_{6}\right]$ as supporting electrolyte. 


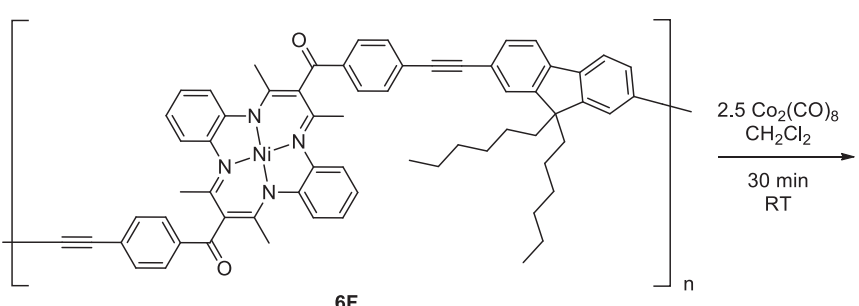

$6 \mathrm{~F}$

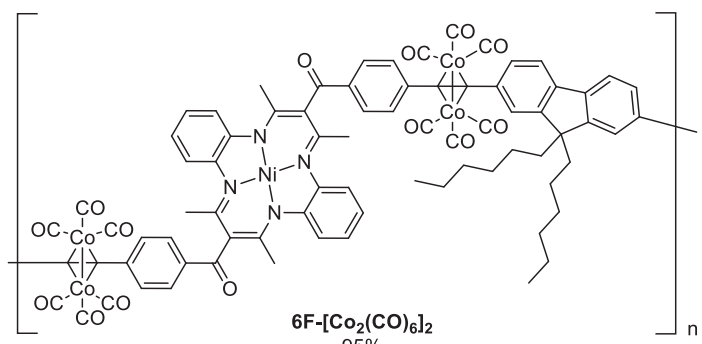

SCHEME 3 Synthesis of $6 \mathrm{~F}-\left[\mathrm{Co}_{2}(\mathrm{CO})_{6}\right]_{2}$.

wave $\mathrm{E}_{\mathrm{pc}(1)}=0.74 \mathrm{~V}$. The irreversible oxidation at $1.11 \mathrm{~V}$ has been reported to arise due to the oxidation of a dimer formed via radical coupling of two equivalents of the radical cation form of similar Ni(II) complexes of Goedken's macrocycle. ${ }^{69}$

Furthermore, Ni(II) complexes of Goedken's macrocycle have been shown to form polymeric species on electrode surfaces. ${ }^{70}$ Upon cycling repeatedly between 0.0 and $1.3 \mathrm{~V}$, film formation was observed in the case of $\mathbf{1 1}$, but there was a lack of current enhancement typically associated with electropolymerization (Figure S11). ${ }^{28}$ Rather, we presume that a variety of oligomeric species are generated upon oxidation, leading to similar oxidation events $(\mathrm{E}=0.6-0.9 \mathrm{~V})$ and electrode plating being observed. ${ }^{71}$

\section{Post-Polymerization Functionalization}

In order to produce a heterobimetallic copolymer, $6 \mathbf{F}$ was dissolved in $\mathrm{CH}_{2} \mathrm{Cl}_{2}$ and reacted with 2.5 equiv. of $\mathrm{Co}_{2}(\mathrm{CO})_{8}$. The resulting copolymer was purified using flash column chromatography on alumina and repeated precipitations from $\mathrm{CH}_{2} \mathrm{Cl}_{2}$ into pentane, to afford $\mathbf{6} \mathbf{F}-\left[\mathrm{Co}_{2}(\mathbf{C O})_{6}\right]_{2}$ in $95 \%$ yield (Scheme 3). GPC analysis of $\mathbf{6 F}-\left[\mathrm{Co}_{2}(\mathrm{CO})_{6}\right]_{2}$ yielded $\mathrm{M}_{\mathrm{n}}=$ $7,700 \mathrm{~g} \mathrm{~mol}^{-1}, \mathrm{M}_{\mathrm{w}}=10,900 \mathrm{~g} \mathrm{~mol}^{-1}$, and $Ð=1.41$. The overall distribution and shape of the GPC traces are conserved when compared to the original polymer $\mathbf{6 F}$ (Figure S12), which
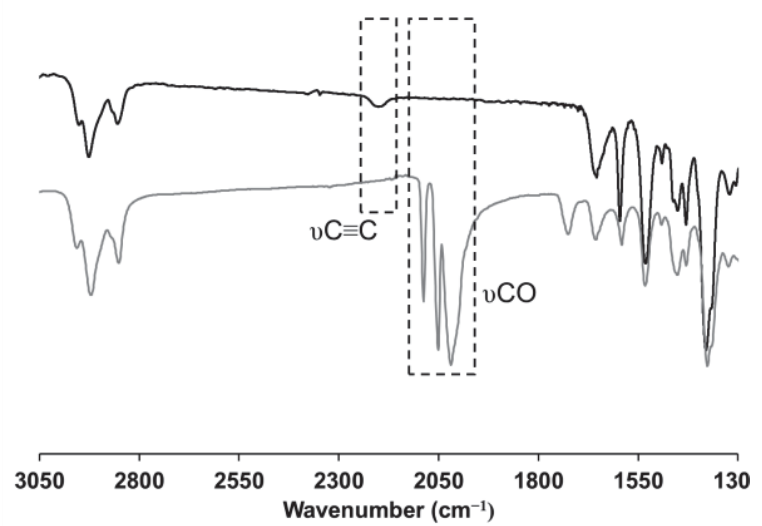

FIGURE 3 FT-IR spectra of $6 \mathrm{~F}$ (black) and $6 \mathrm{~F}-\left[\mathrm{Co}_{2}(\mathrm{CO})_{6}\right]_{2}$ (grey). The dashed boxes highlight the energy regions of specific interest. suggests the integrity of the polymer backbone was maintained after the introduction of the cobalt carbonyl clusters.

UV-vis absorption spectroscopy confirmed the preservation of the absorption maxima at 587, 385, and $270 \mathrm{~nm}$ when compared to the parent polymer $\mathbf{6 F}$ (Figure S13), although the molar absorptivity of the absorption maxima at $385 \mathrm{~nm}$ was reduced from $\varepsilon=100,800 \mathrm{M}^{-1} \mathrm{~cm}^{-1}$ in $\mathbf{6 F}$ to $\varepsilon=$ $71,500 \mathrm{M}^{-1} \mathrm{~cm}^{-1}$ in $\mathbf{6} \mathbf{F}-\left[\mathbf{C O} 2(\mathbf{C O})_{6}\right]_{2}$ and the molar absorptivity of the absorption maxima at $275 \mathrm{~nm}$ was increased from $\varepsilon=$ $50,900 \mathrm{M}^{-1} \mathrm{~cm}^{-1}$ in $6 \mathrm{~F}$ to $\varepsilon=85,900 \mathrm{M}^{-1} \mathrm{~cm}^{-1}$ in $\mathbf{6 F}-$ $\left[\mathrm{Co}_{2}(\mathrm{CO})_{6}\right]_{2}$. Furthermore, analysis of the FT-IR spectrum of $6 \mathrm{~F}-\left[\mathrm{Co}_{2}(\mathrm{CO})_{6}\right]_{2}$ revealed the appearance of three diagnostic carbonyl stretches at 2019, 2051, and $2088 \mathrm{~cm}^{-1}$, and the disappearance of the alkyne $\mathrm{C} \equiv \mathrm{C}$ stretch at $2196 \mathrm{~cm}^{-1}$ (Figure 3). ${ }^{1} \mathrm{H}$ NMR spectroscopy revealed similar chemical shifts for most of the proton signals present in $6 \mathbf{F}$ and $6 \mathbf{F}-\left[\mathrm{Co}_{2}(\mathrm{CO})_{6}\right]_{\mathbf{2}}$ copolymers, although there was a significant difference for some of the chemical shifts of the signals corresponding to the protons present on the fluorene organic spacer, including the aromatic and aliphatic signals (Figure S14).

\section{Thermal Analysis}

Thermal gravimetric analysis (TGA) of copolymers 6F, 6T, and $6 \mathrm{~B}$ demonstrated their thermal stability up to temperatures

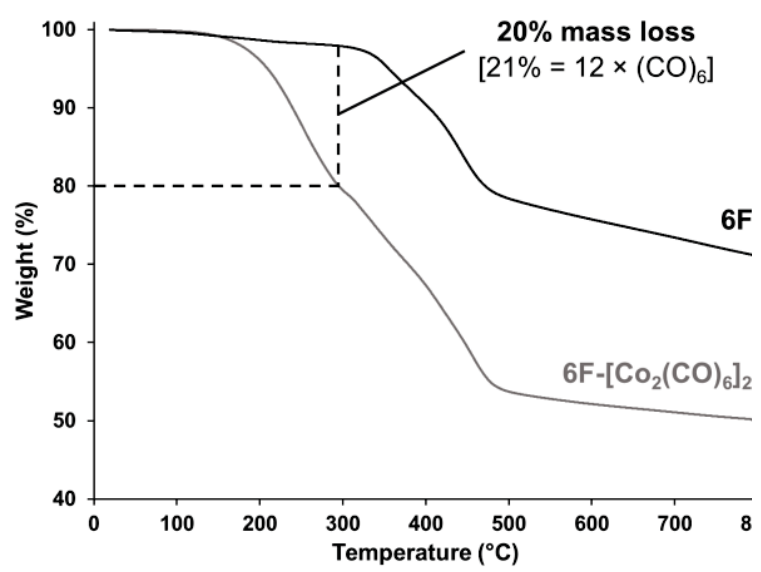

FIGURE 4 TGA data demonstrating the thermal decomposition of $6 \mathrm{~F}$ (black) and $6 \mathrm{~F}-\left[\mathrm{Co}_{2}(\mathrm{CO})_{6}\right]_{2}$ (grey). 
of 316, 284, and $252^{\circ} \mathrm{C}$, respectively (Figures 4, S15, and S16). Differential scanning calorimetry studies did not reveal glass transitions between 0 and $250{ }^{\circ} \mathrm{C}$ (Figures S17-S19). We speculate that the lack of observable glass transitions may be attributed to interdigitation of the alkyl chains present on the backbones of these polymers.

TGA data collected for copolymer $\mathbf{6 F}-\left[\mathrm{Co}_{2}(\mathbf{C O})_{6}\right]_{2}$ showed its thermal stability up to $177^{\circ} \mathrm{C}$ before decomposition occurred in two steps. The first decomposition occurred to a temperature of $c a .300{ }^{\circ} \mathrm{C}$ with an initial mass loss of $c a .20 \%$. This mass loss accounts for the expulsion of the carbonyl groups present on the polymer backbone, which corresponds to $21 \%$ of the total polymer mass. The second step resulted in a further mass loss of $46 \%$ to a temperature of $490{ }^{\circ} \mathrm{C}$, and was followed by a slow thermal degradation until a char yield of $50 \%$ was achieved at $800{ }^{\circ} \mathrm{C}$ (Figure 4). For comparison, the char yield observed for $\mathbf{6 F}$ was $c a$. $70 \%$. Upon inspection of the TGA data for $6 \mathrm{~F}$ and $6 \mathrm{~F}-\left[\mathrm{Co}_{2}(\mathrm{CO})_{6}\right]_{2}$, there were similar degradation features after the initial loss of the carbonyl groups once the thermal stability limit was reached at $316^{\circ} \mathrm{C}$. The DSC data for $\mathbf{6} \mathbf{F}-\left[\mathrm{Co}_{2}(\mathrm{CO})_{6}\right]_{2}$ did not reveal a glass transition within the stability window of the polymer (Figure S20).

\section{Pre-Ceramic Properties}

The interesting thermal decomposition characteristics and significant char yields ( $>50 \%$ ) observed for $6 \mathbf{F}$ and $6 \mathbf{F}$ $\left[\mathrm{Co}_{2}(\mathrm{CO})_{6}\right]_{2}$ suggested the formation of potentially useful ceramic materials. Specifically, Ni/Co alloys were targeted due to their demonstrated utility as magnetic materials, ${ }^{72}$ their use in catalysis, ${ }^{73-74}$ and their high charge capacity. ${ }^{75}$ Thin-films of 6F and $6 \mathrm{~F}-\left[\mathrm{Co}_{2}(\mathrm{CO})_{6}\right]_{2}$, estimated to be approximately $5 \mu \mathrm{m}$ thick (Figure S21), were created by drop-casting a $20 \mathrm{mg} \mathrm{mL}^{-1}$ solution of each polymer in chlorobenzene onto a silicon wafer. The loaded wafers were then dried overnight in a vacuum oven at $60{ }^{\circ} \mathrm{C}$ before the samples were heated to $800^{\circ} \mathrm{C}$ at a rate of
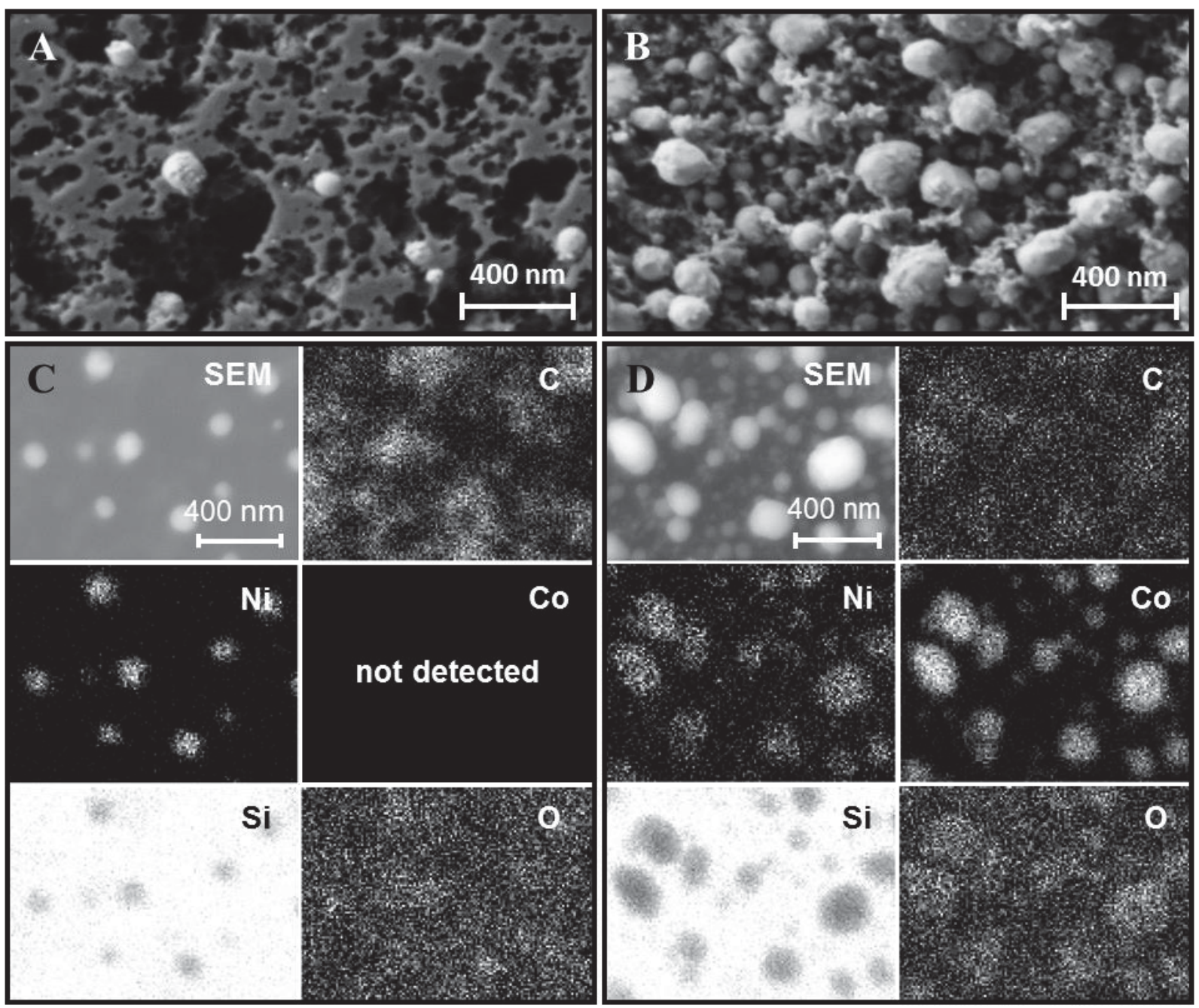

FIGURE 5 Scanning electron micrographs of the nanomaterials resulting from pyrolysis of $A$ ) $6 \mathrm{~F}$ and $\mathrm{B}) \mathbf{6}^{6} \mathrm{~F}-\left[\mathrm{Co} 2(\mathrm{CO})_{6}\right]_{2}$. Elemental maps (EDX spectroscopy) of the nanomaterials resulting from the pyrolysis of $\mathrm{C}$ ) $6 \mathrm{~F}$ and $\mathrm{D}) 6 \mathrm{~F}-\left[\mathrm{Co}_{2}(\mathrm{CO})_{6}\right]_{2}$. Light areas indicate a positive response for the elements in question. 
$10{ }^{\circ} \mathrm{C} \mathrm{min}^{-1}$ and held at that temperature for an additional $3 \mathrm{~h}$ under a $\mathrm{N}_{2} / \mathrm{H}_{2}$ (95:5) atmosphere. Upon cooling, the samples were studied using scanning electron microscopy (SEM) and energy-dispersive X-ray (EDX) spectroscopy.

SEM images of the pyrolyzed films of $6 \mathrm{~F}$ and $\mathbf{6 F}-\left[\mathrm{Co}_{2}(\mathrm{CO})_{6}\right]_{2}$ are shown in Figure 5. The micrographs of the nanomaterials derived from $6 \mathbf{F}$ show the presence of ill-defined nanoparticles within a porous matrix. Based on our EDX spectroscopy analysis we conclude that the nickel-rich nanoparticles are suspended in a porous and amorphous carbon matrix, presumably carbon black (Figures 5a, c). Oxygen appeared throughout the film and was concentrated in metal-rich areas. Although the pyrolysis experiments were performed in the absence of oxygen, brief exposure likely led to the formation of a thin layer of nickel-oxide. The micrograph of the nanomaterials that resulted from the pyrolysis of $6 \mathbf{F}$ $\left[\mathrm{Co}_{2}(\mathrm{CO})_{6}\right]_{2}$ showed a surface more densely populated with metallic nanoparticles within an amorphous carbon matrix (Figure 5b). The nanoparticles were shown to be rich in cobalt and nickel (Figure 5d), while the cobalt and nickel alloys appeared to be more susceptible to oxidation based on the elemental maps obtained (Figure 5d). Furthermore, the ratio of cobalt to nickel ( $c$ a. 5.5:1) was measured by EDX spectroscopy, which deviated from the 4:1 ratio of metals present in $\mathbf{6 F}-\left[\mathrm{Co}_{2}(\mathrm{CO})_{6}\right]_{2}$ (Figure S22). Powder X-ray diffraction studies of the pyrolyzed thin-films of $6 \mathbf{F}$ and $6 \mathbf{F}$ $\left[\mathrm{Co}_{2}(\mathrm{CO})_{6}\right]_{2}$ indicated the presence of amorphous materials, consistent with the morphologies observed using SEM. These studies demonstrated our ability, through post-polymerization functionalization, to control the ratio of metals present within the nanomaterials.

\section{CONCLUSIONS}

Nickel(II) complexes of Goedken's macrocycle bearing alkyne substituents were copolymerized with 2,7-dibromo-9,9dihexylfluorene, 2,5-dibromo-3-hexylthiophene, and 1,4dibromo-2,5-bis(hexyloxy)benzene via a microwave-induced Sonogashira cross-coupling reaction to produce copolymers 6F, 6T, and 6B. The copolymers exhibited high thermal stability (up to $300{ }^{\circ} \mathrm{C}$ ) and two one-electron oxidation waves in their cyclic voltammograms. The spectroscopic properties of copolymer 6F were probed by comparison with model compounds 11 and 12, which provided insight into the observed spectroscopic properties for this family of copolymers. Specifically, the intermediate absorption maxima observed for the copolymers was shown to vary with the size and nature of the organic spacer within the polymer backbones. Post-polymerization functionalization via the alkyne synthetic handle present in $\mathbf{6 F}$ led to the production of heterobimetallic copolymers that produced interesting amorphous nanomaterials rich in nickel and cobalt upon pyrolysis, with metal content influenced by the structure of the polymer.

\section{ACKNOWLEDGEMENTS}

We would like to thank the University of Western Ontario, the Natural Science and Engineering Research Council (NSERC) of Canada (J. B. G.: DG, 435675 and J. A. P.: PGS D scholarship), the Ontario Ministry of Training, Colleges and Universities (J.A.P.: Ontario Graduate Scholarship) the Ontario Ministry of Research and Innovation (J. B. G.: ERA, ER14-10147) and the Canada Foundation for Innovation (J. B. G.: JELF, 33977) for funding this work. We thank Profs. Elizabeth R. Gillies, Michael A. Kerr, and Paul J. Ragogna for access to instrumentation in their labs. Finally, we acknowledge Dr. Todd Simpson and Tim Goldhawk at the Western Nanofabrication Facility and Amir Rabiee Kenaree for their assistance with SEM and EDX spectroscopy studies.

\section{REFERENCES AND NOTES}

1 Y. Lu, N. Yeung, N. Sieracki, N. M. Marshall, Nature 2009, 460, 855-862.

2 C.-L. Ho, W.-Y. Wong, Coord. Chem. Rev. 2011, 255, 2469-2502.

3 G. R. Whittell, M. D. Hager, U. S. Schubert, I. Manners, Nat. Mater. 2011, 10, 176-188.

4 B. Bagh, J. B. Gilroy, A. Staubitz, J. Muller, J. Am. Chem. Soc. 2010, 132, 1794-1795.

5 Y. Zha, H. D. Thaker, R. R. Maddikeri, S. P. Gido, M. T. Tuominen, G. N. Tew, J. Am. Chem. Soc. 2012, 134, 14534-14541.

6 X. Wang, K. Cao, Y. Liu, B. Tsang, S. Liew, J. Am. Chem. Soc. 2013, 135, 3399-3402.

7 M. Hadadpour, Y. Liu, P. Chadha, P. J. Ragogna, Macromolecules 2014, 47, 6207-6217.

8 G. M. Pawar, R. A. Lalancette, E. M. Bonder, J. B. Sheridan, F. Jäkle, Macromolecules 2015, 48, 6508-6515.

9 B. Sandmann, B. Happ, S. Kupfer, F. H. Schacher, M. D. Hager, U. S. Schubert, Macromol. Rapid Commun. 2015, 36, 604-609.

10 Y. Yan, J. Zhang, L. Ren, C. Tang, Chem. Soc. Rev. 2016, 10.1039/C36CS00026F.

11 X. Feng, K. Zhang, M. A. Hempenius, G. J. Vancso, RSC Adv. 2015, 5, 106355-106376.

12 R. Rulkens, A. J. Lough, I. Manners, S. R. Lovelace, C. Grant, W. E. Geiger, J. Am. Chem. Soc. 1996, 118, 12683-12695.

13 Y. Ma, W.-F. Dong, M. A. Hempenius, H. Möhwald, G. J. Vancso, Nat. Mater. 2006, 5, 724-729.

14 R. H. Staff, M. Gallei, M. Mazurowski, M. Rehahn, R. Berger, K. Landfester, D. Crespy, ACS Nano 2012, 6, 9042-9049.

15 A. Rabiee Kenaree, B. M. Berven, P. J. Ragogna, J. B. Gilroy, Chem. Commun. 2014, 50, 10714-10717.

16 K. Zhang, X. Feng, X. Sui, M. A. Hempenius, G. J. Vancso, Angew. Chem. Int. Ed. 2014, 53, 13789-13793.

17 M. J. MacLachlan, M. Ginzburg, N. Coombs, T. W. Coyle, N. P. Raju, J. E. Greedan, G. A. Ozin, I. Manners, Science 2000, 287, 1460-1463.

18 T. J. O'Sullivan, B. Djukic, P. A. Dube, M. T. Lemaire, Chem. Commun. 2009, 1903-1905. 
19 Z. M. Al-Badri, R. R. Maddikeri, Y. Zha, H. D. Thaker, P. Dobriyal, R. Shunmugam, T. P. Russell, G. N. Tew, Nat. Commun. 2011, 2, 482.

20 S. Baljak, A. D. Russell, S. C. Binding, M. F. Haddow, D. O'Hare, I. Manners, J. Am. Chem. Soc. 2014, 136, 5864-5867.

21 H. Braunschweig, A. Damme, S. Demeshko, K. Dück, T. Kramer, I. Krummenacher, F. Meyer, K. Radacki, S. Stellwag-Konertz, G. R. Whittell, J. Am. Chem. Soc. 2015, 137, 1492-1500.

22 B. Jiang, W. L. Hom, X. Chen, P. Yu, L. C. Pavelka, K. Kisslinger, J. B. Parise, S. R. Bhatia, R. B. Grubbs, J. Am. Chem. Soc. 2016, 138, 4616-4625.

23 C. Ulbricht, B. Beyer, C. Friebe, A. Winter, U. S. Schubert, Adv. Mater. 2009, 21, 4418-4441.

24 C. Ulbricht, C. R. Becer, A. Winter, U. S. Schubert, Macromol. Rapid Commun. 2010, 31, 827-833.

25 A. M. Soliman, D. Fortin, E. Zysman-Colman, P. D. Harvey, Macromol. Rapid Commun. 2012, 33, 522-527.

26 A. Wild, A. Teichler, C.-L. Ho, X.-Z. Wang, H. Zhan, F. Schlütter, A. Winter, M. D. Hager, W.-Y. Wong, U. S. Schubert, J. Mater. Chem. C 2013, 1, 1812-1822.

27 Y. Matsumura, K. Fukuda, S. Inagi, I. Tomita, Macromol. Rapid Commun. 2015, 36, 660-664.

28 B. J. Holliday, T. M. Swager, Chem. Commun. 2005, 23-36.

29 C. Moorlag, B. C. Sih, T. L. Stott, M. O. Wolf, J. Mater. Chem. 2005, 15, 2433-2436.

30 W.-Y. Wong, P. D. Harvey, Macromol. Rapid Commun. 2010, 31, 671-713.

31 C. Friebe, M. D. Hager, A. Winter, U. S. Schubert, Adv. Mater. 2012, 24, 332-345.

32 K. R. Edelman, K. J. Stevenson, B. J. Holliday, Macromol. Rapid Commun. 2012, 33, 610-615

33 C. Friebe, B. Schulze, H. Görls, M. Jäger, U. S. Schubert, Chem. Eur. J. 2014, 20, 2357-2366.

34 J. D. Caraway, M. T. Nguyen, L. A. Mitchell, B. J. Holliday, Macromol. Rapid Commun. 2015, 36, 665-670.

35 W.-Y. Wong, C.-L. Ho, Acc. Chem. Res. 2010, 43, 1246-1256.

36 M. Yang, L. Zhang, Z. Lei, P. Ye, J. Si, Q. Yang, Y. Wang, J. Appl. Polym. Sci. 1998, 70, 1165-1172.

37 W.-Y. Wong, X.-Z. Wang, Z. He, A. B. Djurišić, C.-T. Yip, K.-Y. Cheung, H. Wang, C. S. K. Mak, W.-K. Chan, Nat. Mater. 2007, 6, 521-527.

38 C.-L. Ho, S.-Y. Poon, K. Liu, C.-K. Wong, G.-L. Lu, S. Petrov, I. Manners, W.-Y. Wong, J. Organomet. Chem. 2013, 744, 165-171.

39 Q. Dong, G. Li, C.-L. Ho, M. Faisal, C.-W. Leung, P. W.-T. Pong, K. Liu, B.-Z. Tang, I. Manners, W.-Y. Wong, Adv. Mater. 2012, 24, 1034-1040

40 K. Liu, C.-L. Ho, S. Aouba, Y.-Q. Zhao, Z.-H. Lu, S. Petrov, N. Coombs, P. Dube, H. E. Ruda, W.-Y. Wong, I. Manners, Angew. Chem. Int. Ed. 2008, 47, 1255-1259.

41 E. Scamporrino, D. Vitalini, Macromolecules 1992, 25, 1625-1632. 42 H. Eichhorn, M. Sturm, D. Wöhrle, Macromol. Chem. Phys. 1995, 196, 115-131.
43 X. Ding, J. Guo, X. Feng, Y. Honsho, J. Guo, S. Seki, P. Maitarad, A. Saeki, S. Nagase, D. Jiang, Angew. Chem. Int. Ed. 2011, 50, 1289-1293.

44 M. Abel, S. Clair, O. Ourdjini, M. Mossoyan, L. Porte, J. Am. Chem. Soc. 2011, 133, 1203-1205.

45 J. Jeong, Y.-J. Lee, B. Kim, B. Kim, K.-S. Jung, H.-j. Paik, Polym. Chem. 2015, 6, 3392-3397.

46 A. C. W. Leung, M. J. MacLachlan, J. Inorg. Organomet. Polym. Mater. 2007, 17, 57-89.

47 R. P. Kingsborough, T. M. Swager, Chem. Mater. 2000, 12, 872-874.

48 T. Shioya, T. M. Swager, Chem. Commun. 2002, 1364-1365.

49 B. J. Holliday, T. B. Stanford, T. M. Swager, Chem. Mater. 2006, 18, 5649-5651.

$50 \mathrm{H}$. Fukumoto, K. Yamane, Y. Kase, T. Yamamoto, Macromolecules 2010, 43, 10366-10375.

51 K. Yagi, M. Ito, H. Houjou, Macromol. Rapid Commun. 2012, 33, 540-544.

52 M. T. Nguyen, B. J. Holliday, Chem. Commun. 2015, 51, 8610-8613.

53 S. Realista, A. S. Viana, B. d. P. Cardoso, A. M. Botelho do Rego, P. D. Vaz, A. I. Melato, P. N. Martinho, M. J. Calhorda, RSC AdV. 2015, 5, 39495-39504.

54 W. Y. Chan, S. B. Clendenning, A. Berenbaum, A. J. Lough, S. Aouba, H. E. Ruda, I. Manners, J. Am. Chem. Soc. 2005, 127, 1765-1772.

55 M. Zamora, S. Bruña, B. Alonso, I. Cuadrado, Macromolecules 2011, 44, 7994-8007.

56 J. Zhang, Y. Yan, J. Chen, W. M. Chance, J. Hayat, Z. Gai, C. Tang, Chem. Mater. 2014, 26, 3185-3190.

57 Q. Dong, G. Li, H. Wang, P. Wing-Tat Pong, C.-W. Leung, I. Manners, C.-L. Ho, H. Li, W.-Y. Wong, J. Mater. Chem. C 2015, 3, 734-741.

58 R. Ciganda, H. Gu, P. Castel, P. Zhao, J. Ruiz, R. Hernández, D. Astruc, Macromol. Rapid Commun. 2016, 37, 105-111.

59 J. A. Paquette, E. R. Sauvé, J. B. Gilroy, Macromol. Rapid Commun. 2015, 36, 621-626.

60 F. A. Cotton, J. Czuchajowska, Polyhedron 1990, 9, 2553-2566.

61 P. Mountford, Chem. Soc. Rev. 1998, 27, 105-115.

62 A. S. Abd-El-Aziz, P. O. Shipman, B. N. Boden, W. S. McNeil, Prog. Polym. Sci. 2010, 35, 714-836.

63 J. Gwyther, J. B. Gilroy, P. A. Rupar, D. J. Lunn, E. Kynaston, S. K. Patra, G. R. Whittell, M. A. Winnik, I. Manners, Chem. Eur. J. 2013, 19, 9186-9197.

64 J. H. Niewahner, K. A. Walters, A. Wagner, J. Chem. Educ. 2007, 84, 477.

65 R. Bernard, C. Barsu, P. L. Baldeck, C. Andraud, D. Cornu, J.-P. Scharff, P. Miele, Chem. Commun. 2008, 3765-3767.

66 C. L. Bailey, R. D. Bereman, D. P. Rillema, R. Nowak, Inorg. Chem. 1984, 23, 3956-3960.

67 N. Fomina, S. E. Bradforth, T. E. Hogen-Esch, Macromolecules 2009, 42, 6440-6447.

68 T.-A. Chen, X. Wu, R. D. Rieke, J. Am. Chem. Soc. 1995, 117, 233-244.

69 F. C. McElroy, J. C. Dabrowiak, J. Am. Chem. Soc. 1976, 98, 7112-7113. 
70 C. L. Bailey, R. D. Bereman, D. P. Rillema, R. Nowak, Inorg. Chem. 1986, 25, 933-938.

71 D. Kim, E. Kim, J. Byun, J. Choi, H. Na, Y. Park, J. Coord. Chem. 2002, 55, 505-516.

72 N. A. M. Barakat, B. Kim, C. Yi, Y. Jo, M.-H. Jung, K. H. Chu, H. Y. Kim, J. Phys. Chem. C 2009, 113, 19452-19457.
73 K. Lian, S. J. Thorpe, D. W. Kirk, Electrochim. Acta 1992, 37, 169-175. 74 R. Xu, T. Xie, Y. Zhao, Y. Li, Nanotechnology 2007, 18, 055602.

75 J. Chang, J. Sun, C. Xu, H. Xu, L. Gao, Nanoscale 2012, 4, 6786-6791. 


\title{
Supporting Information
}

\section{Synthesis, Characterization, and Pre-Ceramic Properties of $\pi$-Conjugated Polymers Based on Ni(II) Complexes of Goedken's Macrocycle}

\author{
Joseph A. Paquette and Joe B. Gilroy*
}

Department of Chemistry and The Centre for Advanced Materials and Biomaterials Research (CAMBR), The University of Western Ontario, 1151 Richmond St. N., London, Ontario, Canada, N6A 5B7. 
A
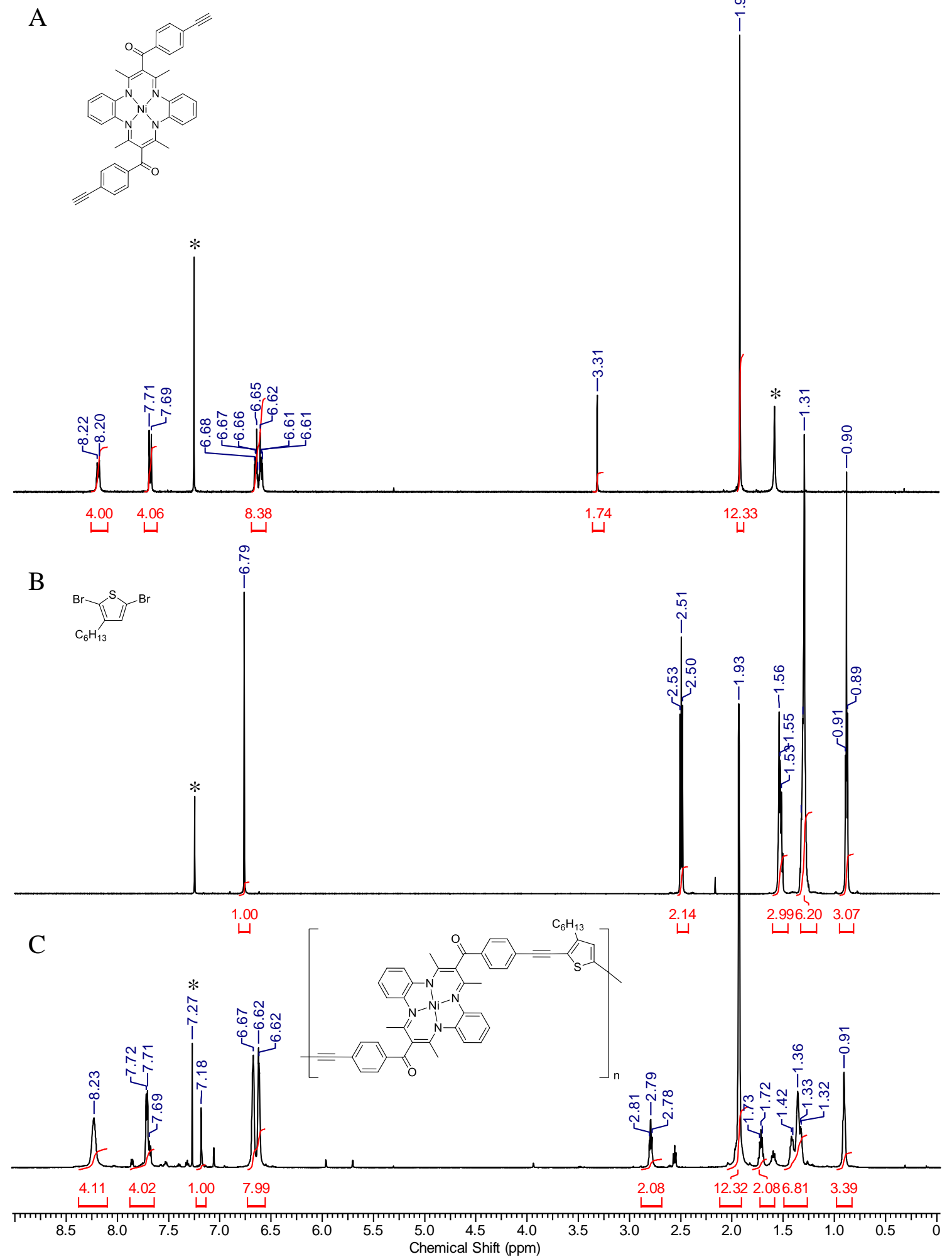

Figure S1. ${ }^{1} \mathrm{H}$ NMR spectra of A) 5, B) 1,4-dibromo-3-hexylthiophene, and C) copolymer 6T in $\mathrm{CDCl}_{3}$. Asterisks denote residual solvent signals. 


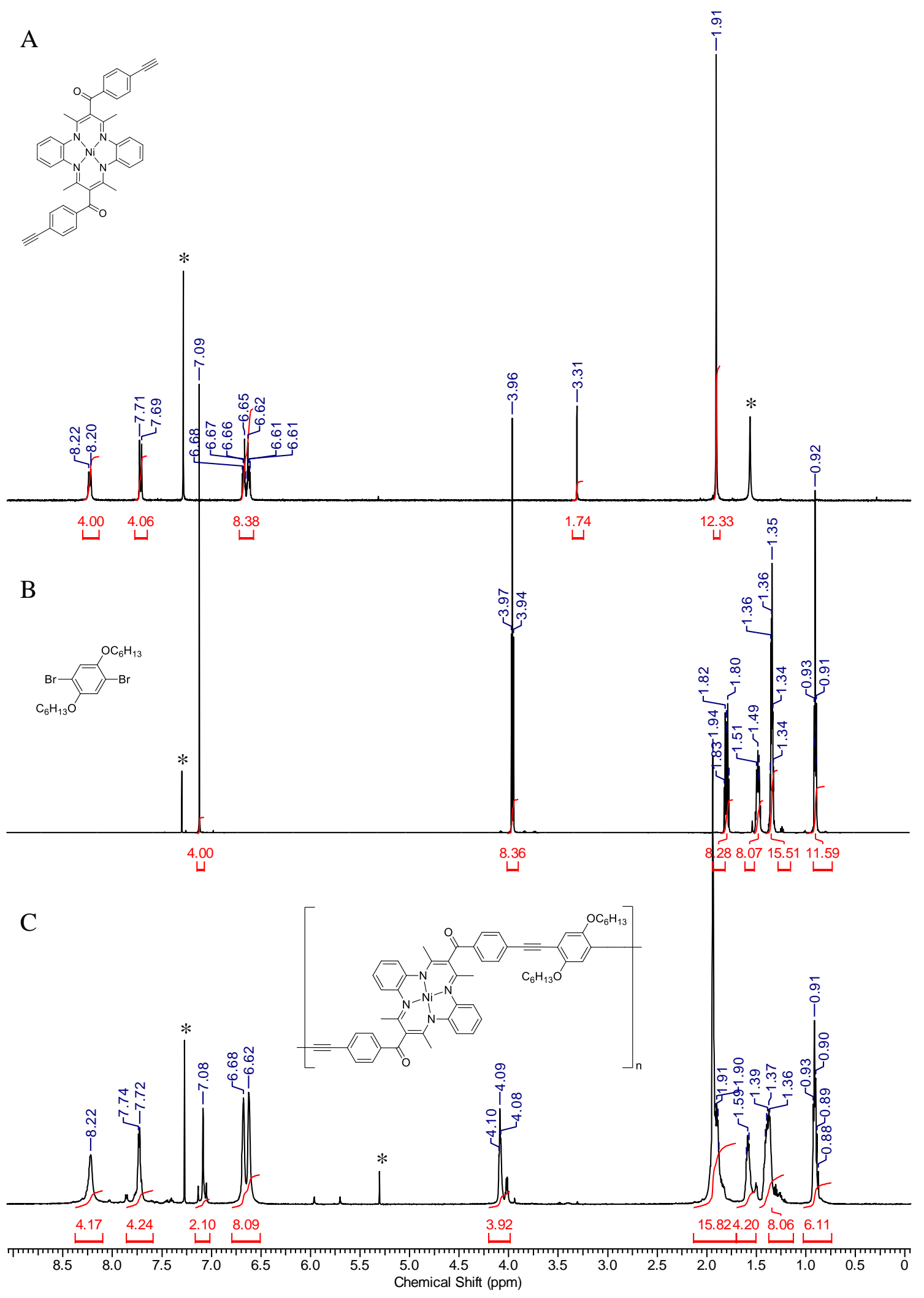

Figure S2. ${ }^{1} \mathrm{H}$ NMR spectra of A) 5, B)1,4-dibromo-2,5-bis(hexyloxy)benzene, and C) copolymer 6B in $\mathrm{CDCl}_{3}$. Asterisks denote residual solvent signals. 

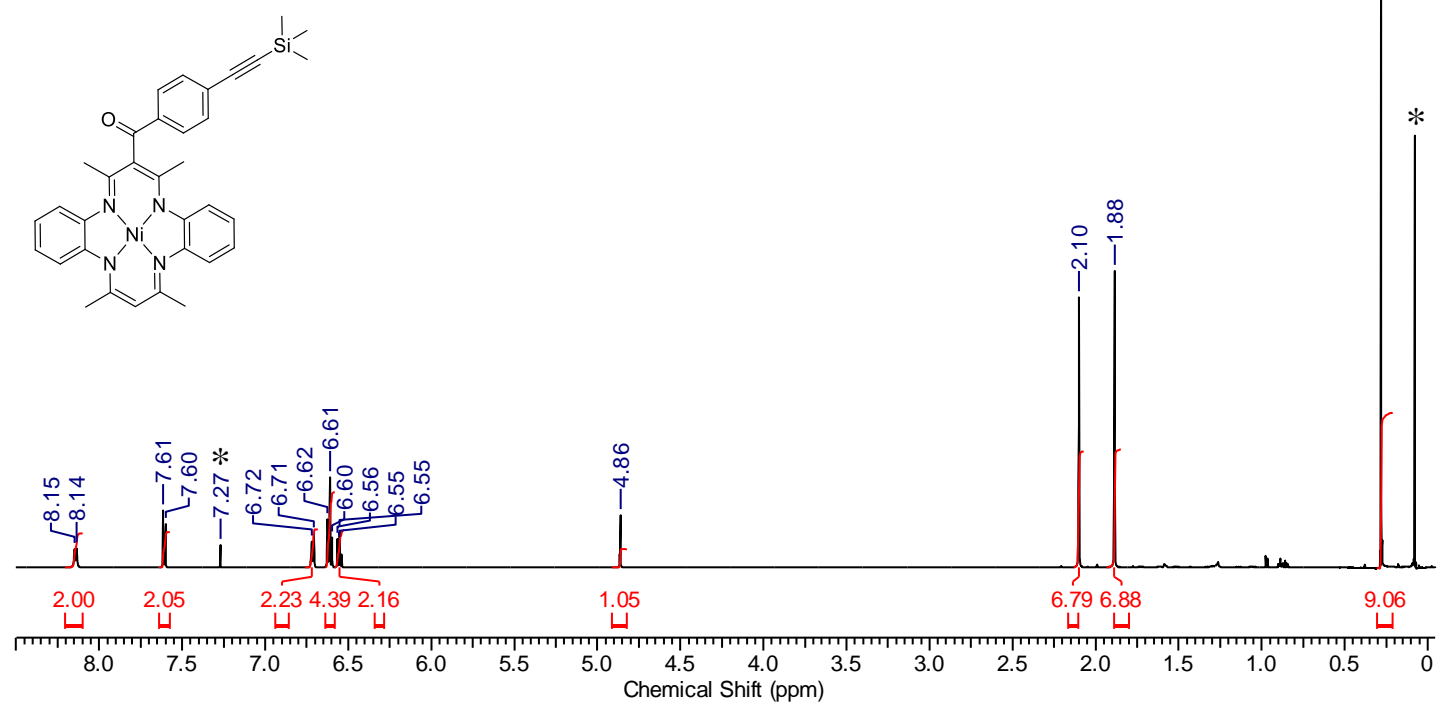

Figure S3. ${ }^{1} \mathrm{H}$ NMR spectrum of $\mathbf{8}$ in $\mathrm{CDCl}_{3}$. Asterisks denote residual solvent and grease signals.

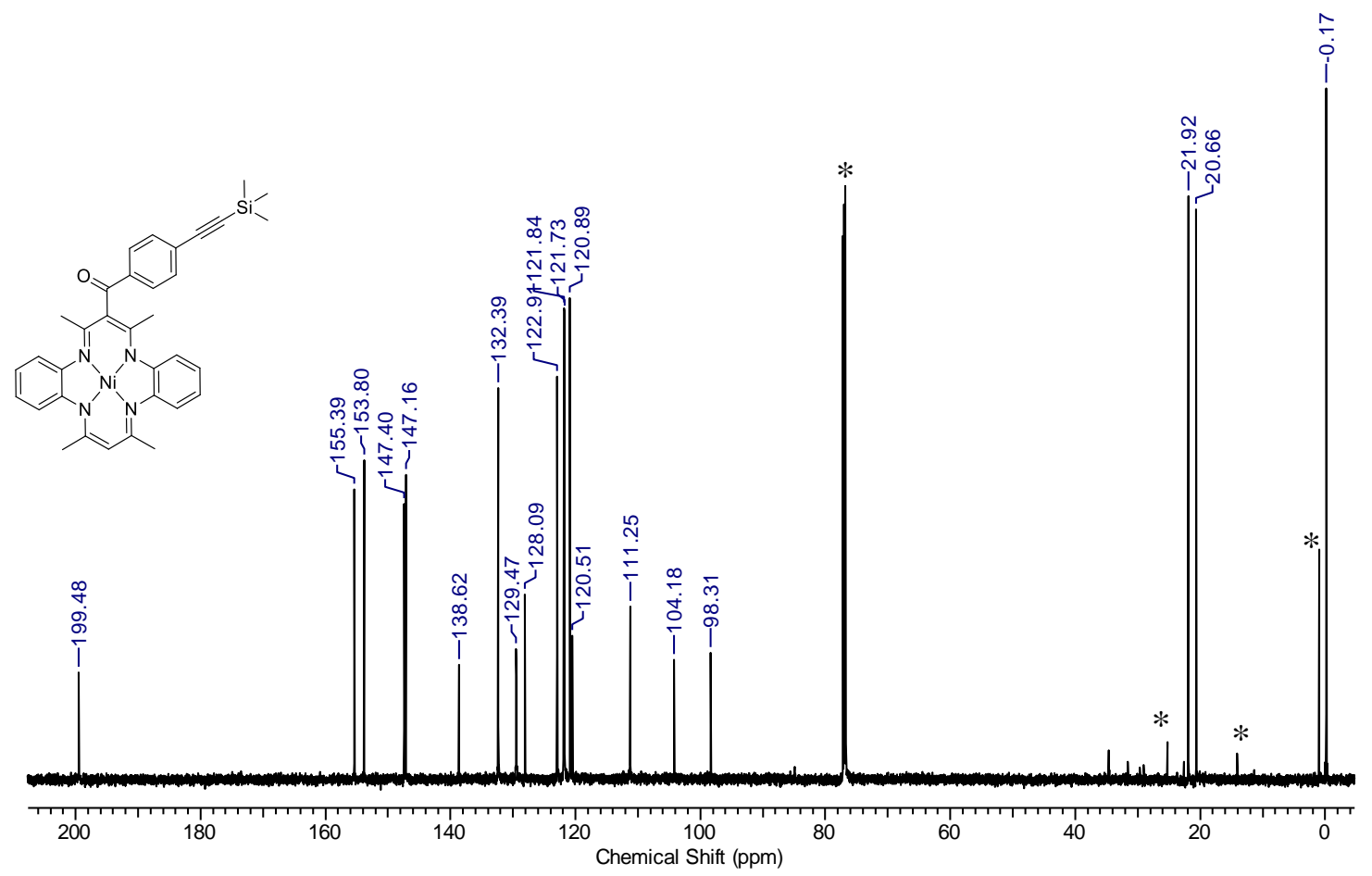

Figure S4. ${ }^{13} \mathrm{C}\left\{{ }^{1} \mathrm{H}\right\}$ NMR spectrum of $\mathbf{8}$ in $\mathrm{CDCl}_{3}$. Asterisks denote solvent and grease signals. 


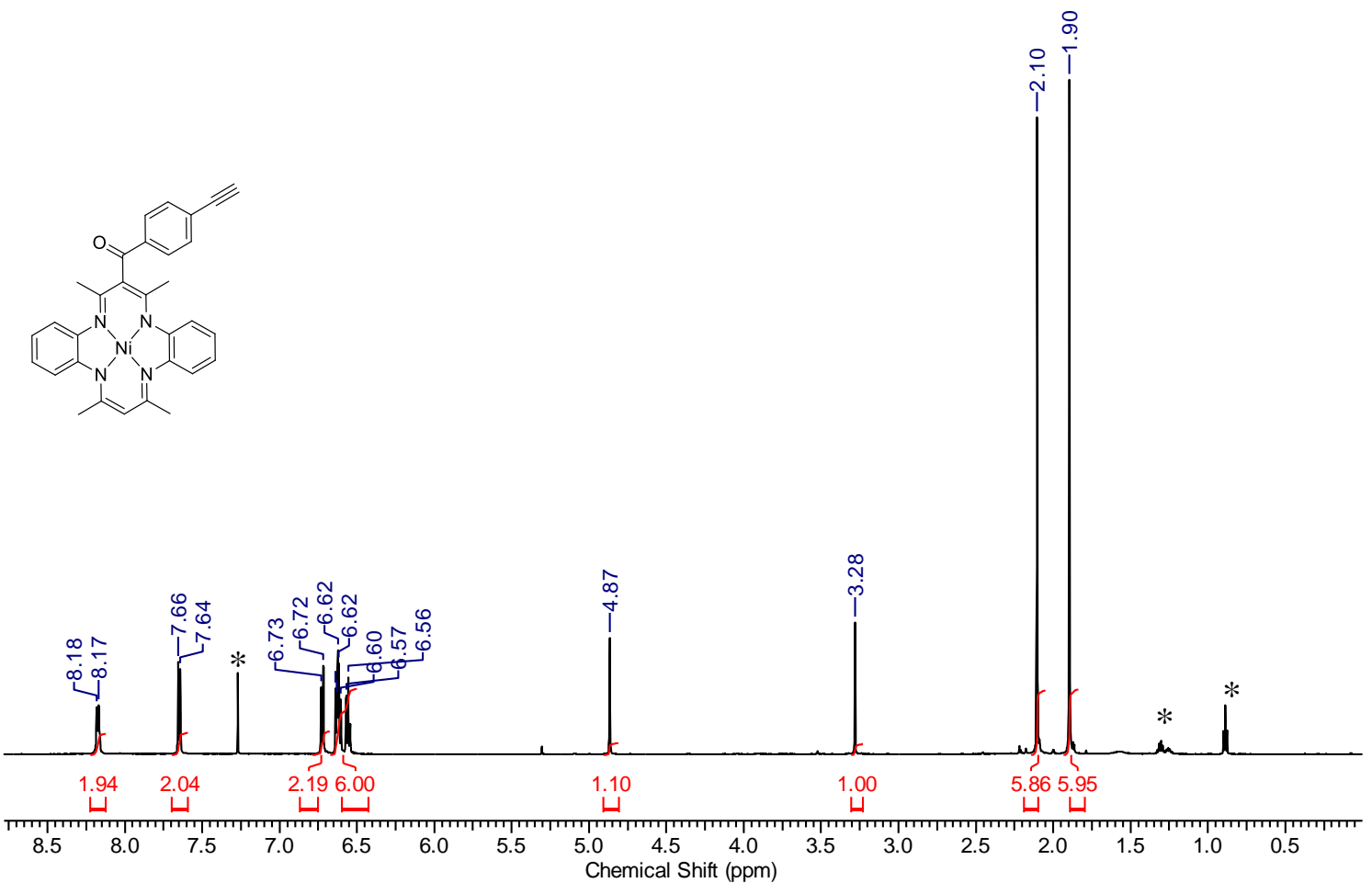

Figure S5. ${ }^{1} \mathrm{H}$ NMR spectrum of $\mathbf{1 0}$ in $\mathrm{CDCl}_{3}$. Asterisks denote residual solvent signals.
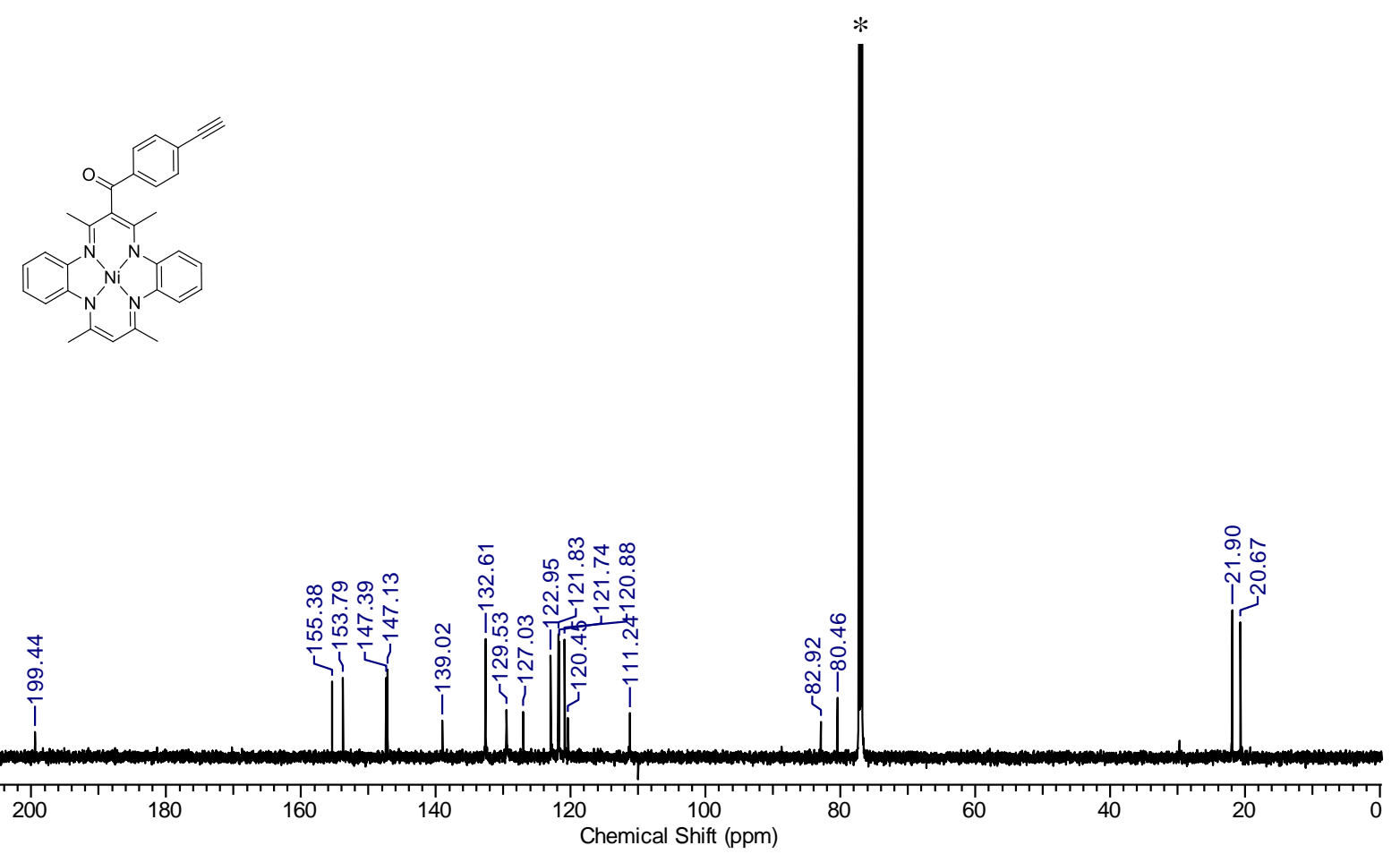

Figure S6. ${ }^{13} \mathrm{C}\left\{{ }^{1} \mathrm{H}\right\}$ NMR spectrum of $\mathbf{1 0}$ in $\mathrm{CDCl}_{3}$. Asterisk denotes solvent signal. 


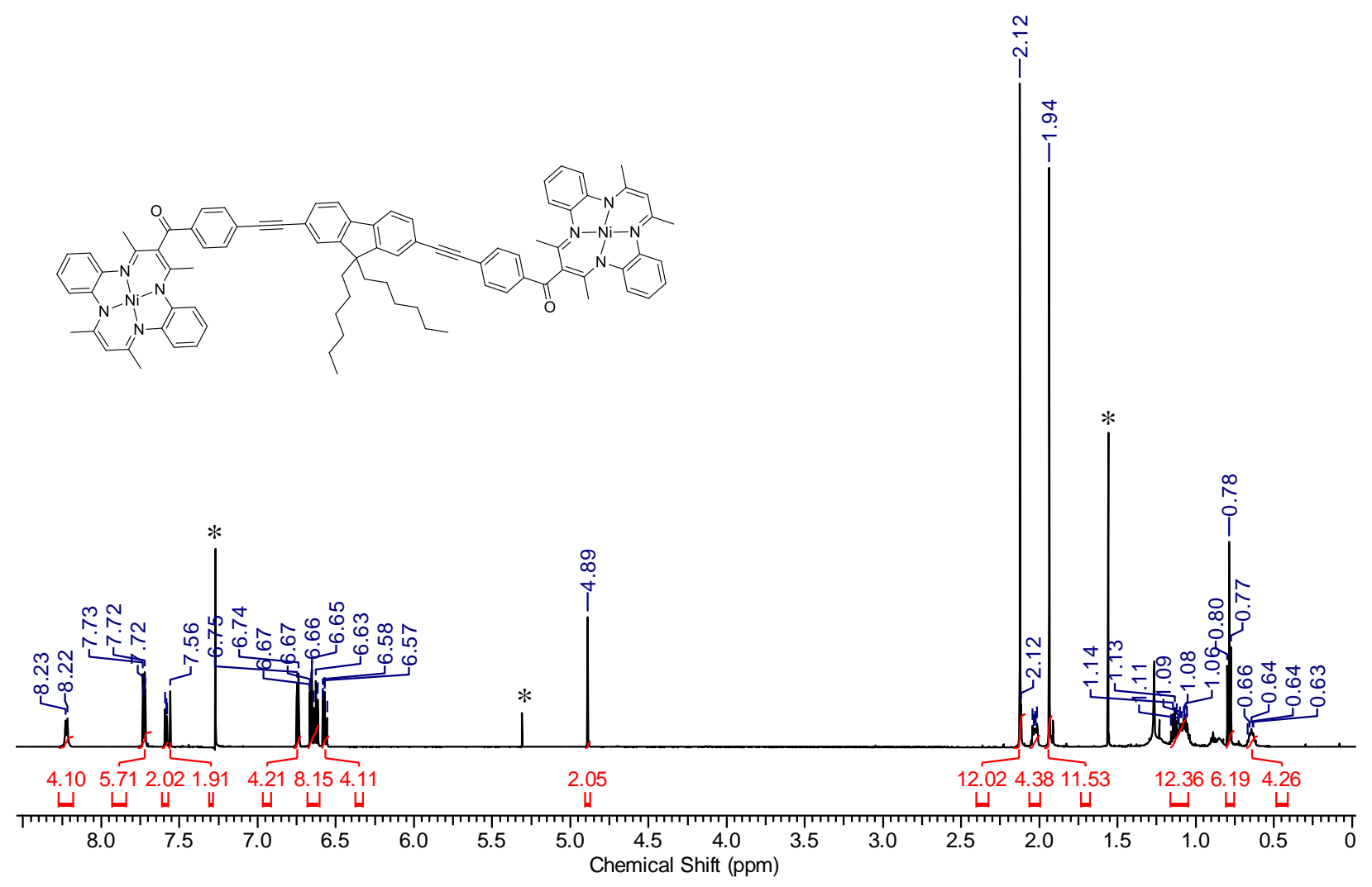

Figure S7. ${ }^{1} \mathrm{H}$ NMR spectrum of 11 in $\mathrm{CDCl}_{3}$. Asterisks denote residual solvent signals.
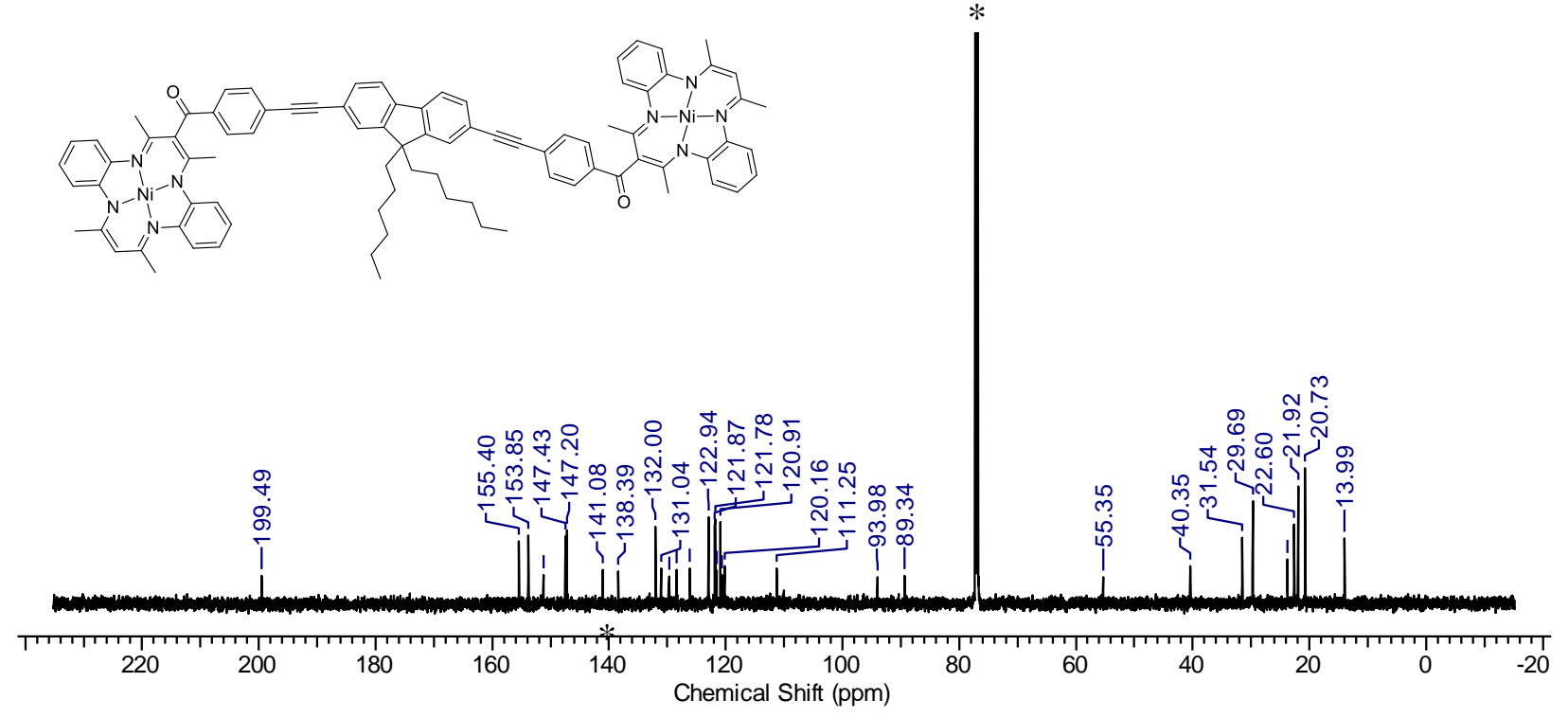

Figure S8. ${ }^{13} \mathrm{C}\left\{{ }^{1} \mathrm{H}\right\}$ NMR spectrum of 11 in $\mathrm{CDCl}_{3}$. Asterisk denotes solvent signal. 

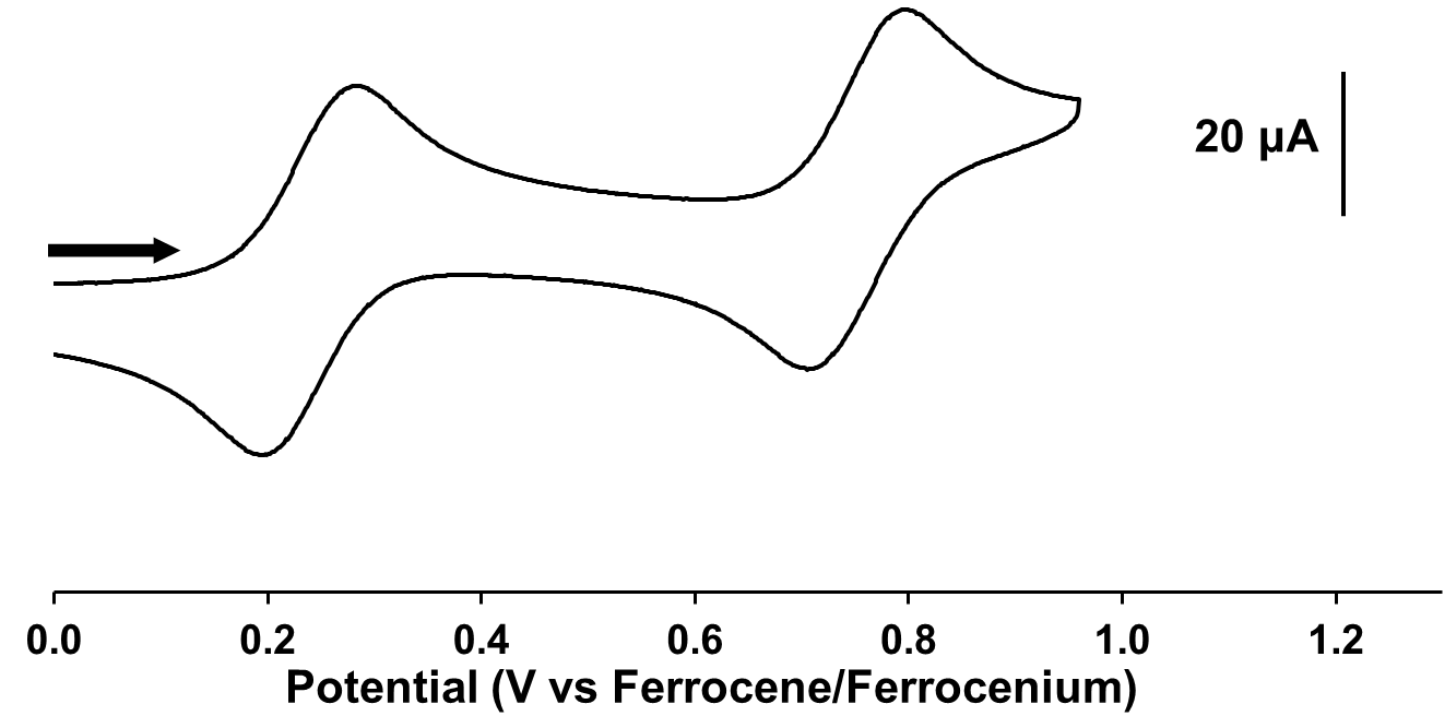

Figure S9. Cyclic voltammagram of model compound 12 recorded at a scan rate of $100 \mathrm{mV} \mathrm{s}^{-1}$ in a $\mathrm{CH}_{2} \mathrm{Cl}_{2}$ solution containing $1 \times 10^{-3} \mathrm{M}$ analyte and $0.1 \mathrm{M}\left[n \mathrm{Bu}_{4} \mathrm{~N}\right]\left[\mathrm{PF}_{6}\right]$ as supporting electrolyte.

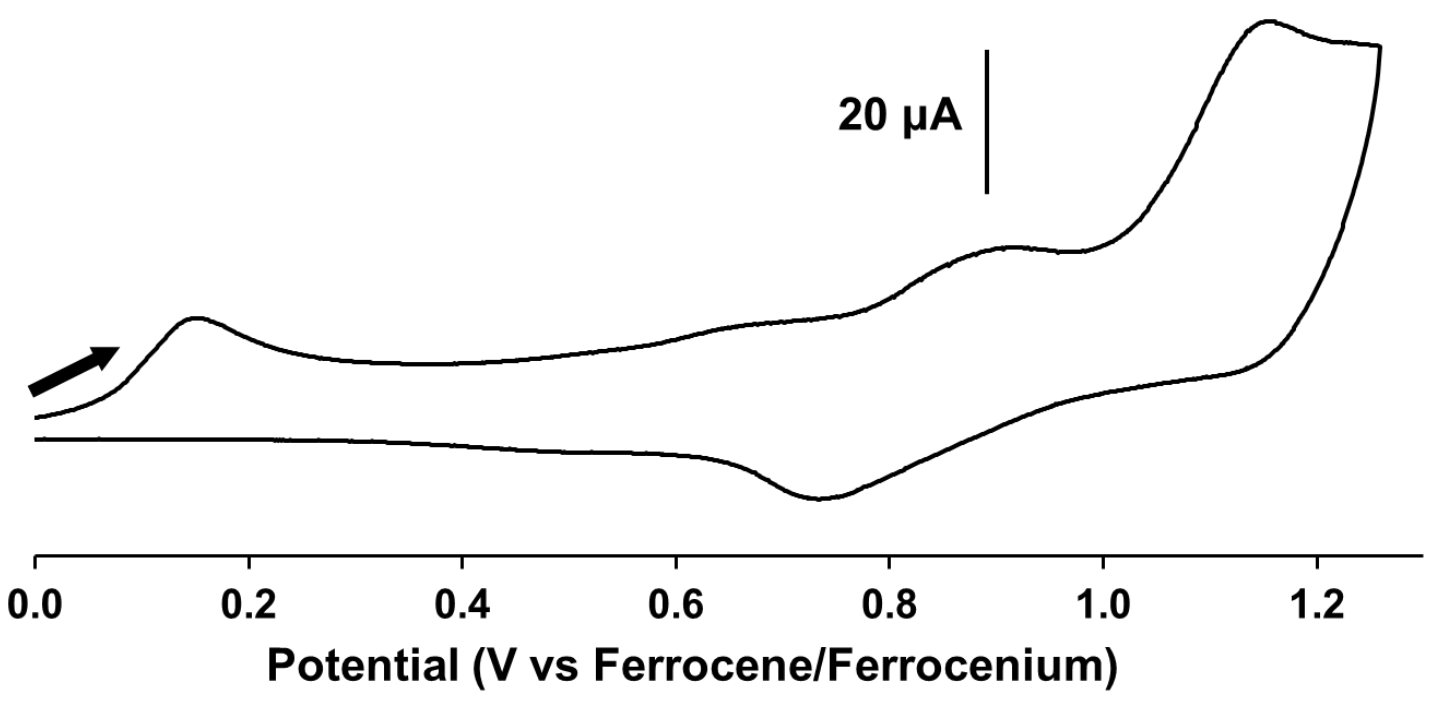

Figure S10. Cyclic voltammagram of model compound 11 recorded at a scan rate of $100 \mathrm{mV} \mathrm{s}^{-1}$ in a $\mathrm{CH}_{2} \mathrm{Cl}_{2}$ solution containing $1 \times 10^{-3} \mathrm{M}$ analyte and $0.1 \mathrm{M}\left[n \mathrm{Bu}_{4} \mathrm{~N}\right]\left[\mathrm{PF}_{6}\right]$ as supporting electrolyte. 


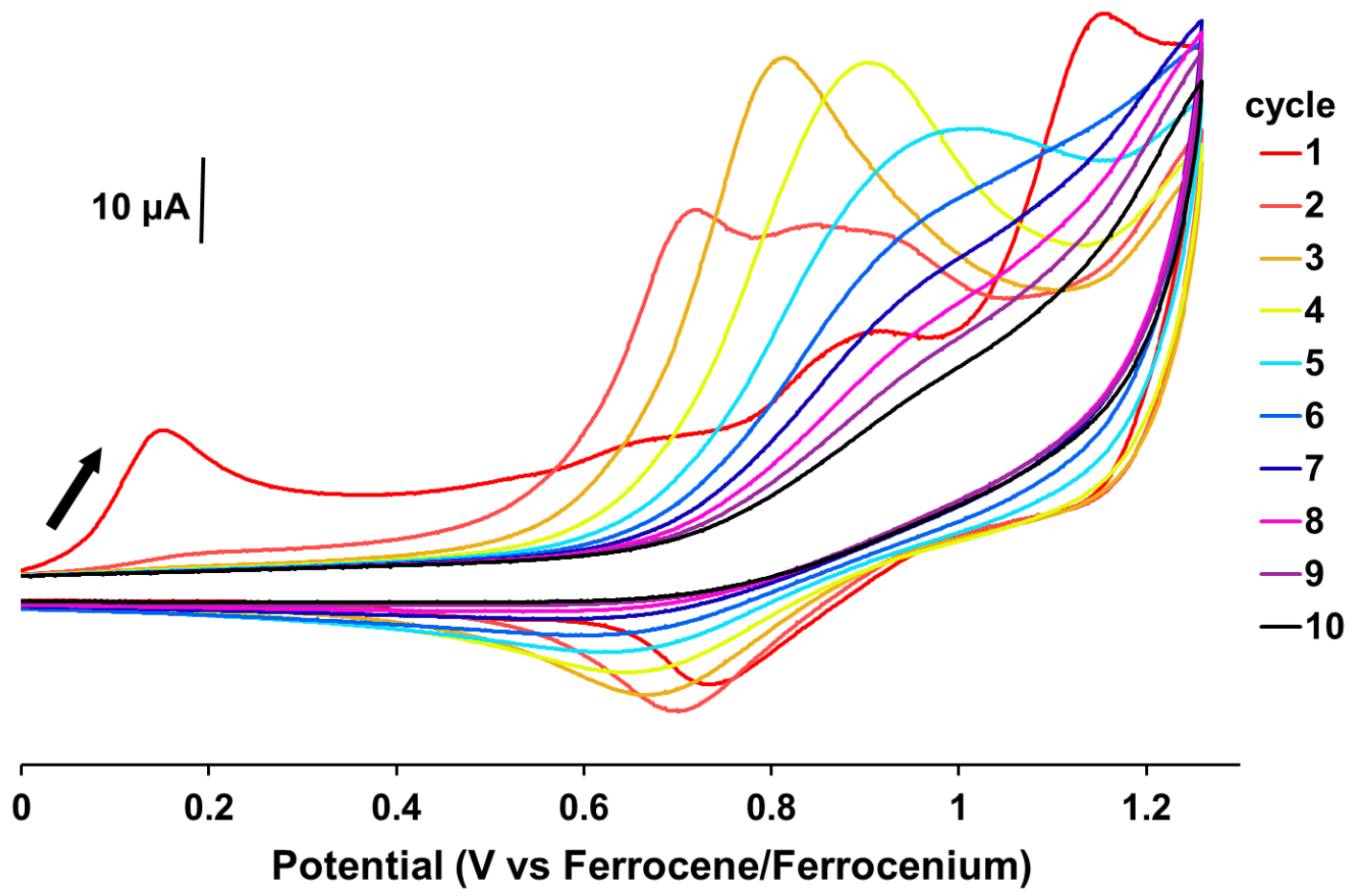

Figure S11. Cyclic voltammagrams of $\mathbf{1 1}$ cycled 10 times and recorded at a scan rate of $250 \mathrm{mV} \mathrm{s}^{-1}$ in a $\mathrm{CH}_{2} \mathrm{Cl}_{2}$ solution containing $1 \times 10^{-3} \mathrm{M}$ analyte and $0.1 \mathrm{M}\left[n \mathrm{Bu}_{4} \mathrm{~N}\right]\left[\mathrm{PF}_{6}\right]$ as supporting electrolyte.

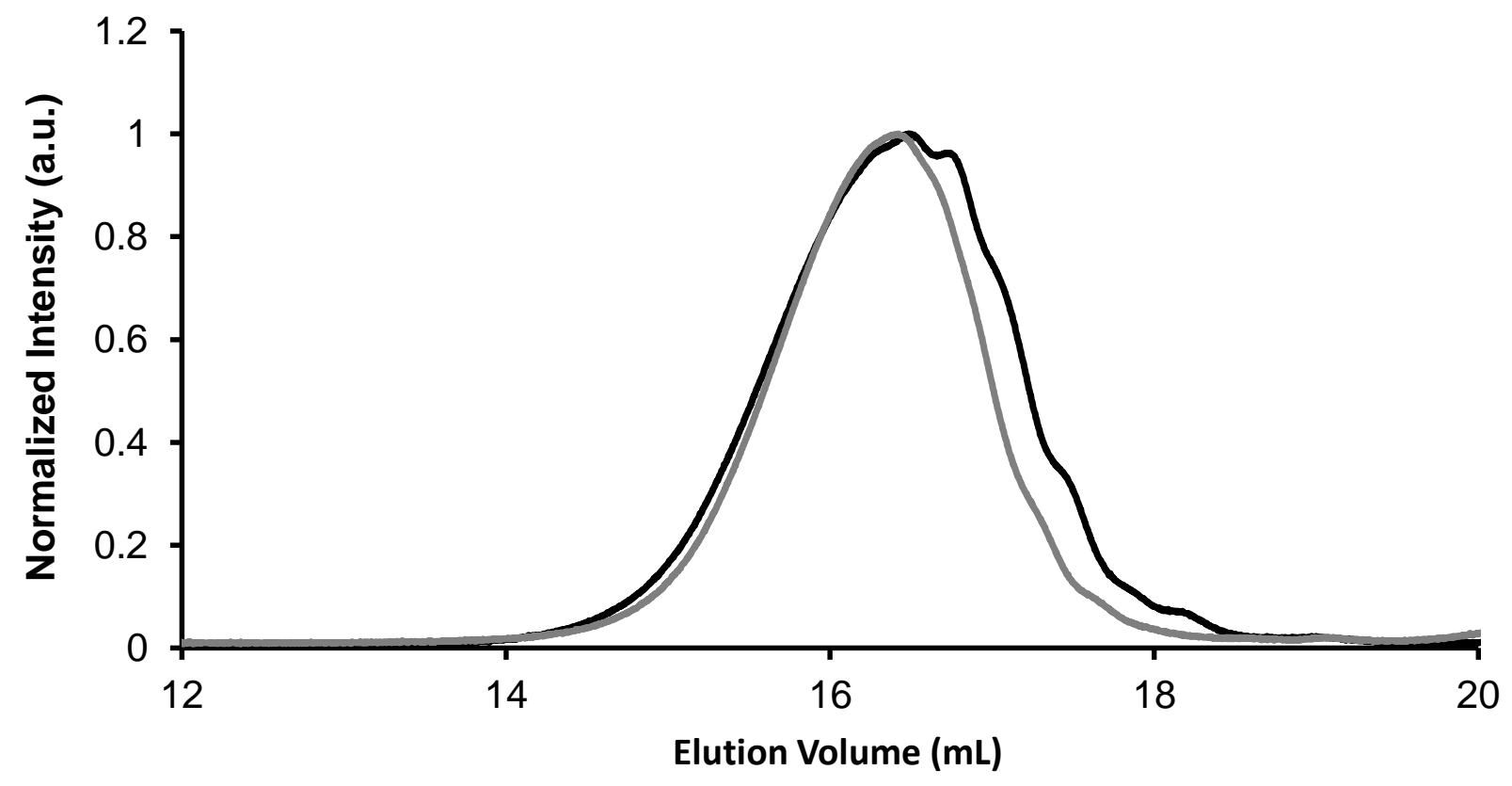

Figure S12. GPC traces for 6F (black) and 6F-[Co2(CO)6]2 (grey). 


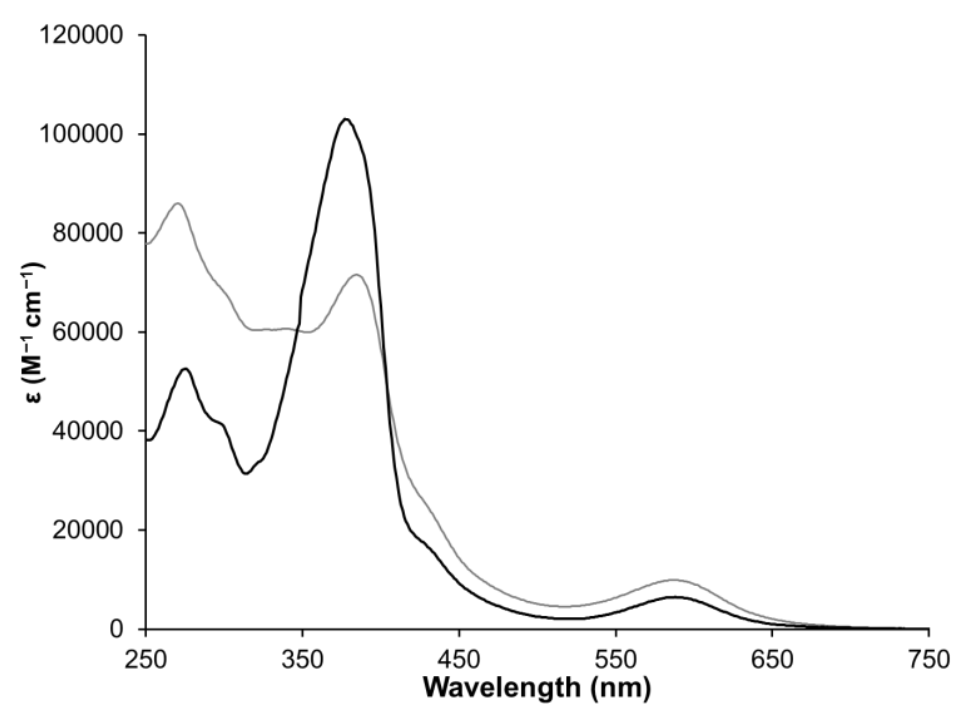

Figure S13. UV-vis absorption spectra of 6F (black) and 6F-[Co2(CO)6 $]_{2}$ (grey) in $\mathrm{CH}_{2} \mathrm{Cl}_{2}$.

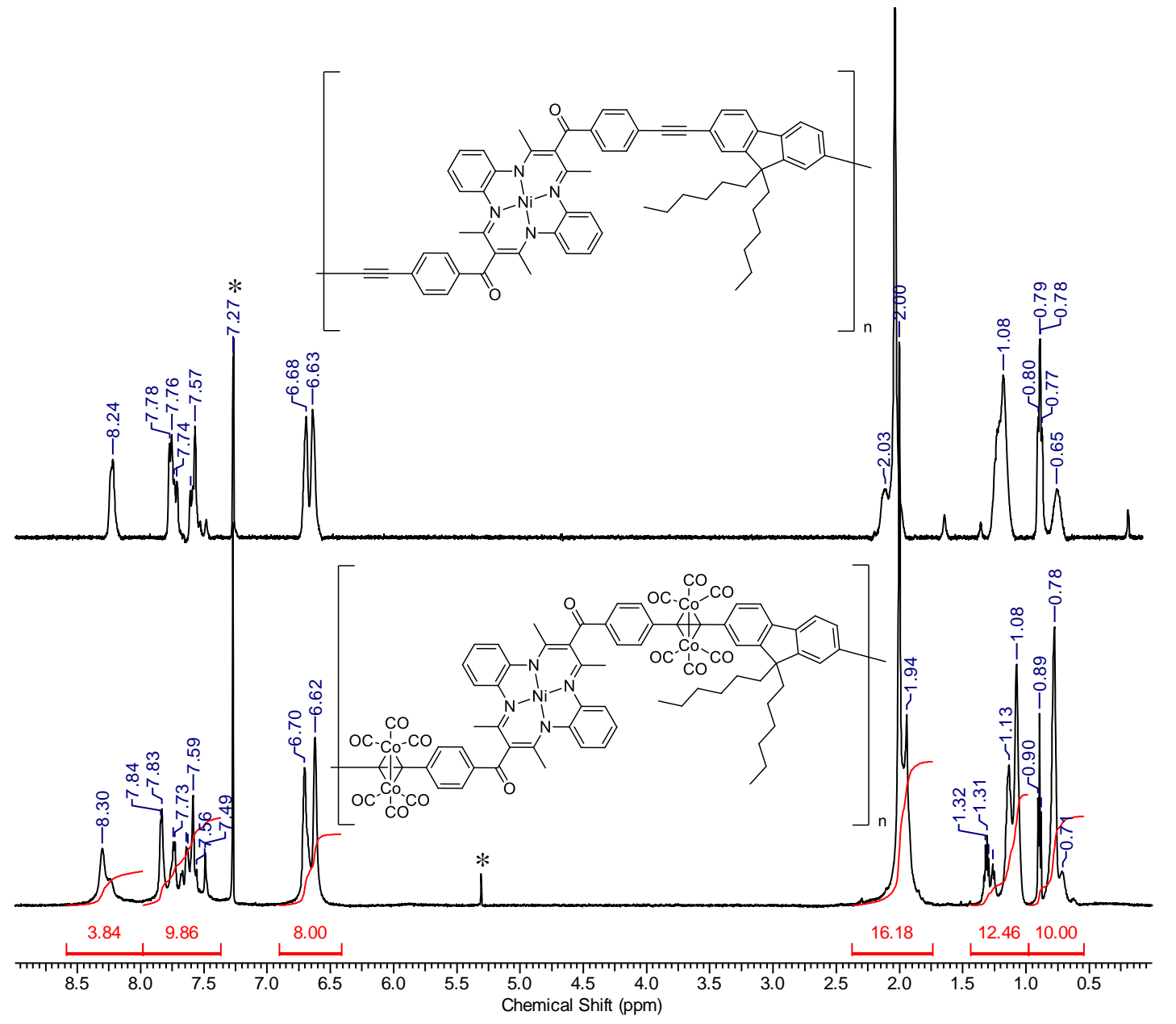

Figure S14. ${ }^{1} \mathrm{H}$ NMR spectrum of $6 \mathrm{~F}$ and $6 \mathrm{~F}-\left[\mathrm{Co}_{2}(\mathrm{CO})_{6}\right]_{2}$ in $\mathrm{CDCl}_{3}$. Asterisks denote residual solvent signals. 


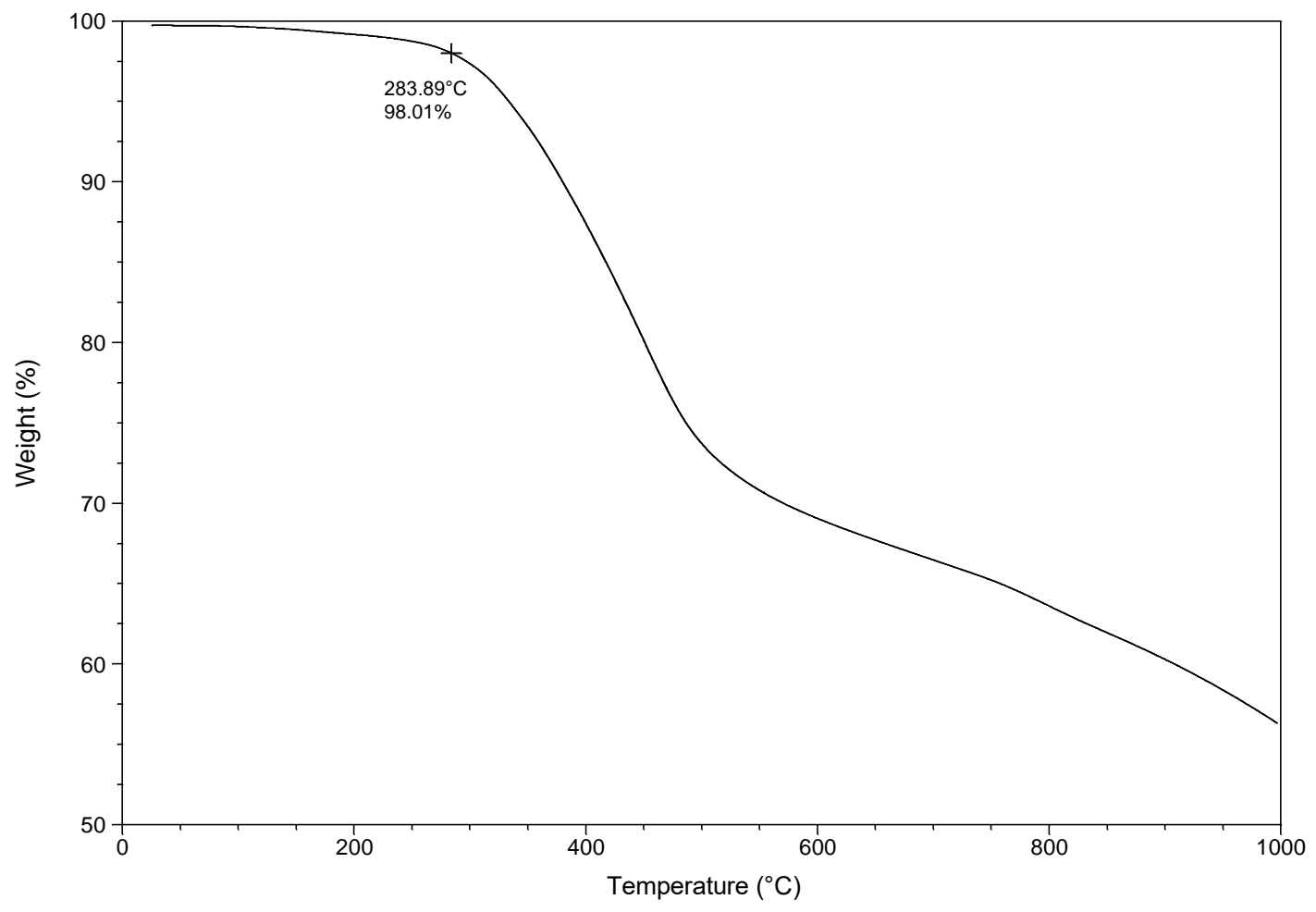

Figure S15. TGA data for 6T.

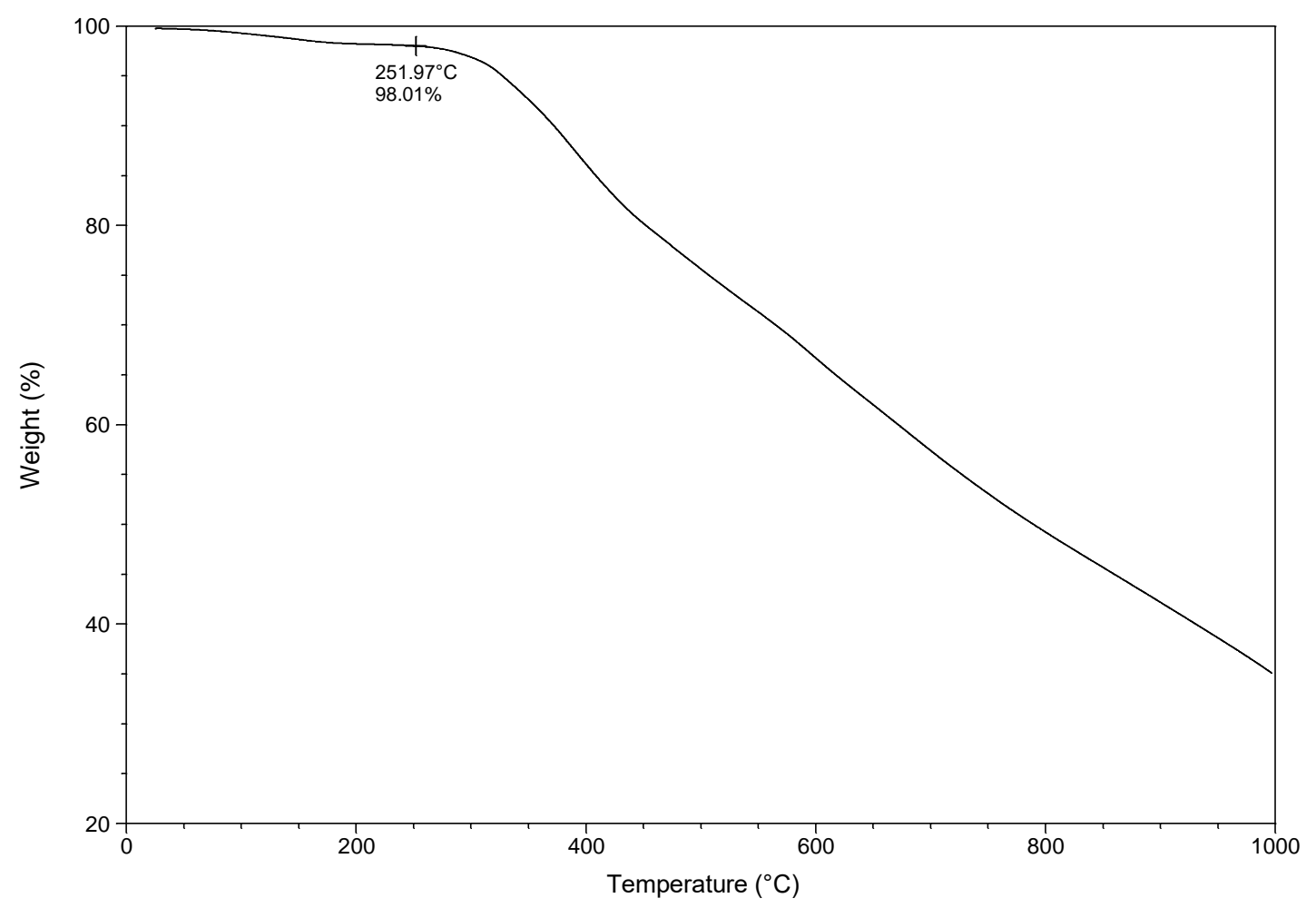

Figure S16. TGA data for $6 \mathrm{~B}$. 


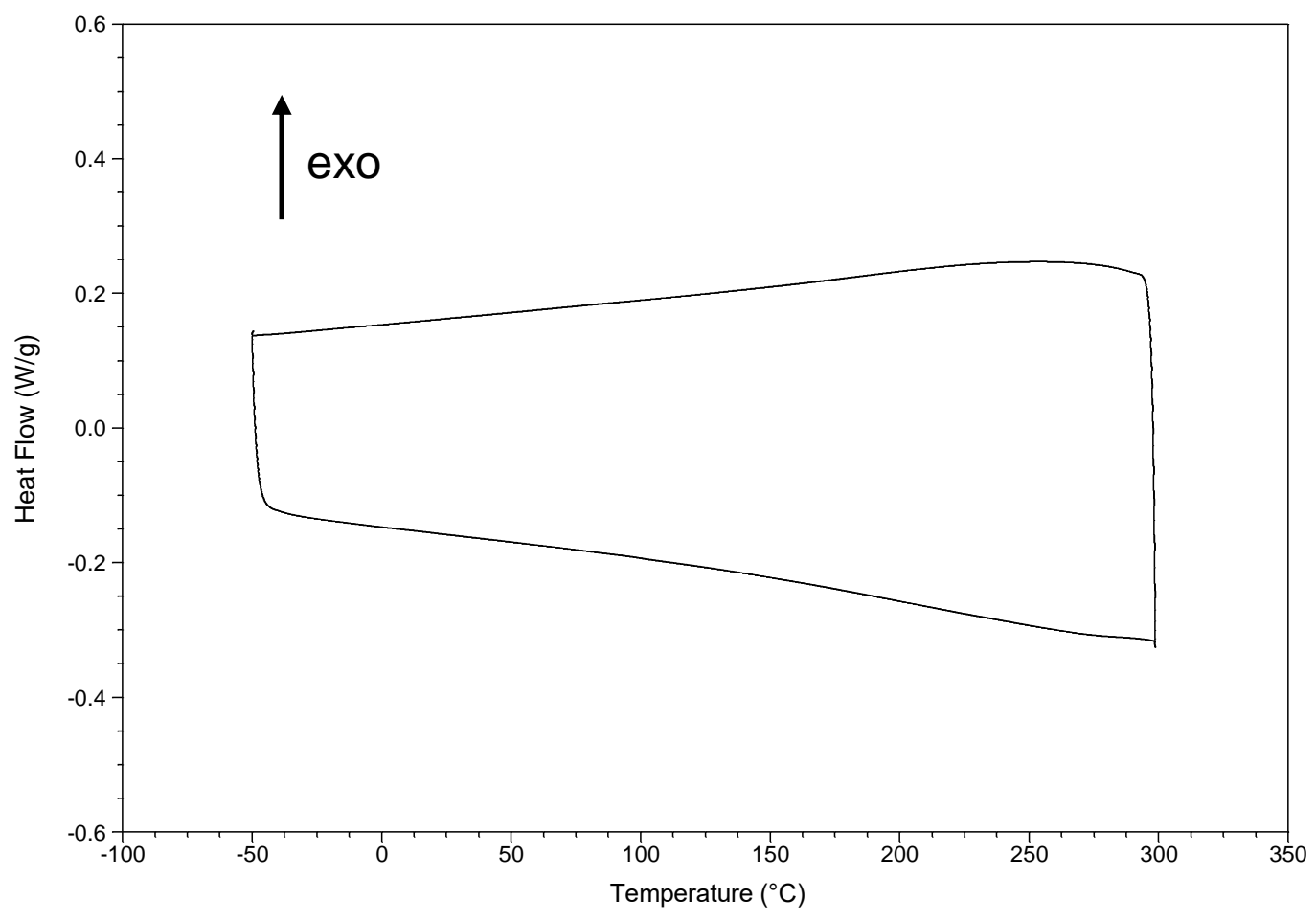

Figure S17. DSC trace for 6F. The second heating/cooling cycle is shown.

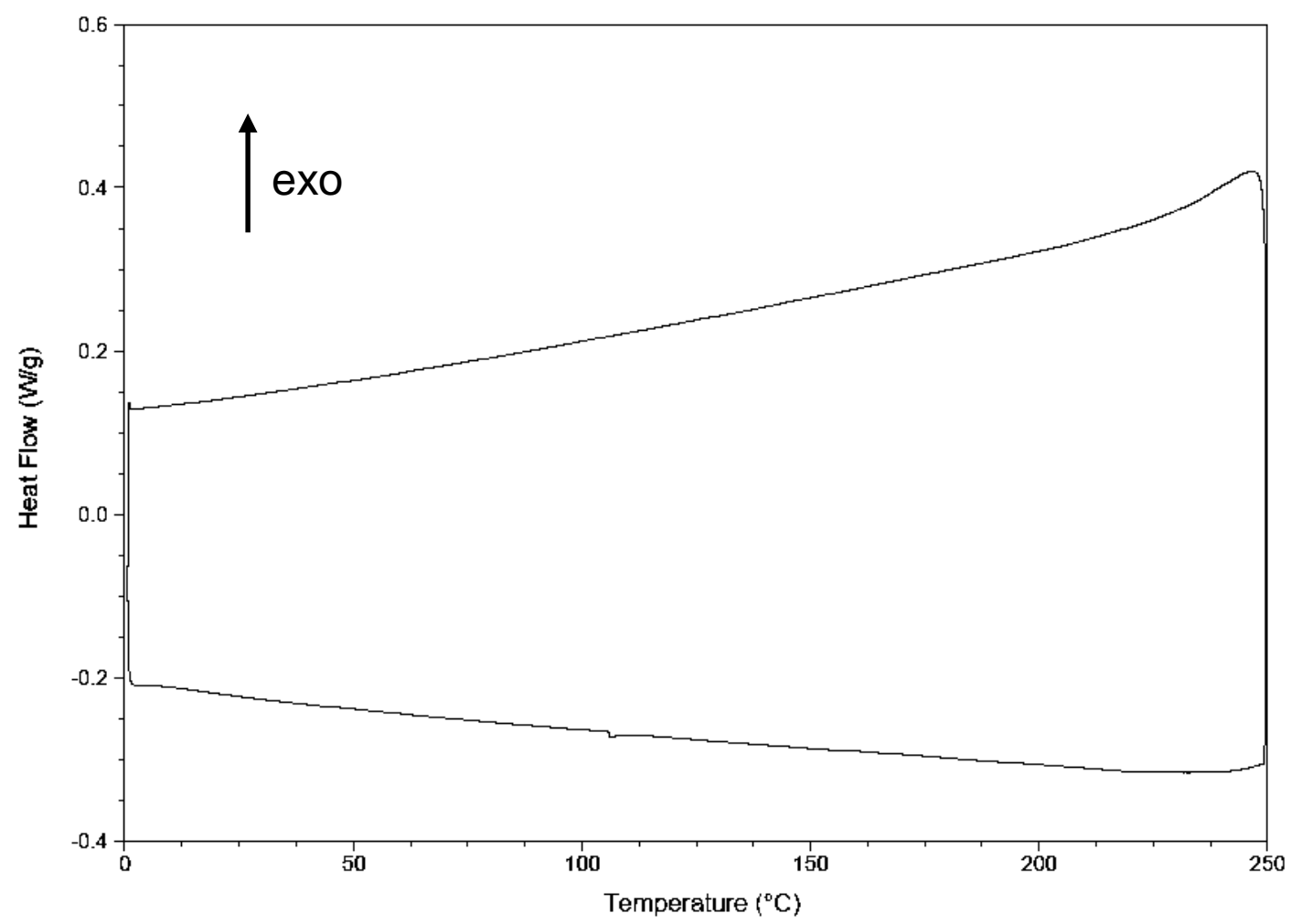

Figure S18. DSC trace for 6T. The second heating/cooling cycle is shown. 


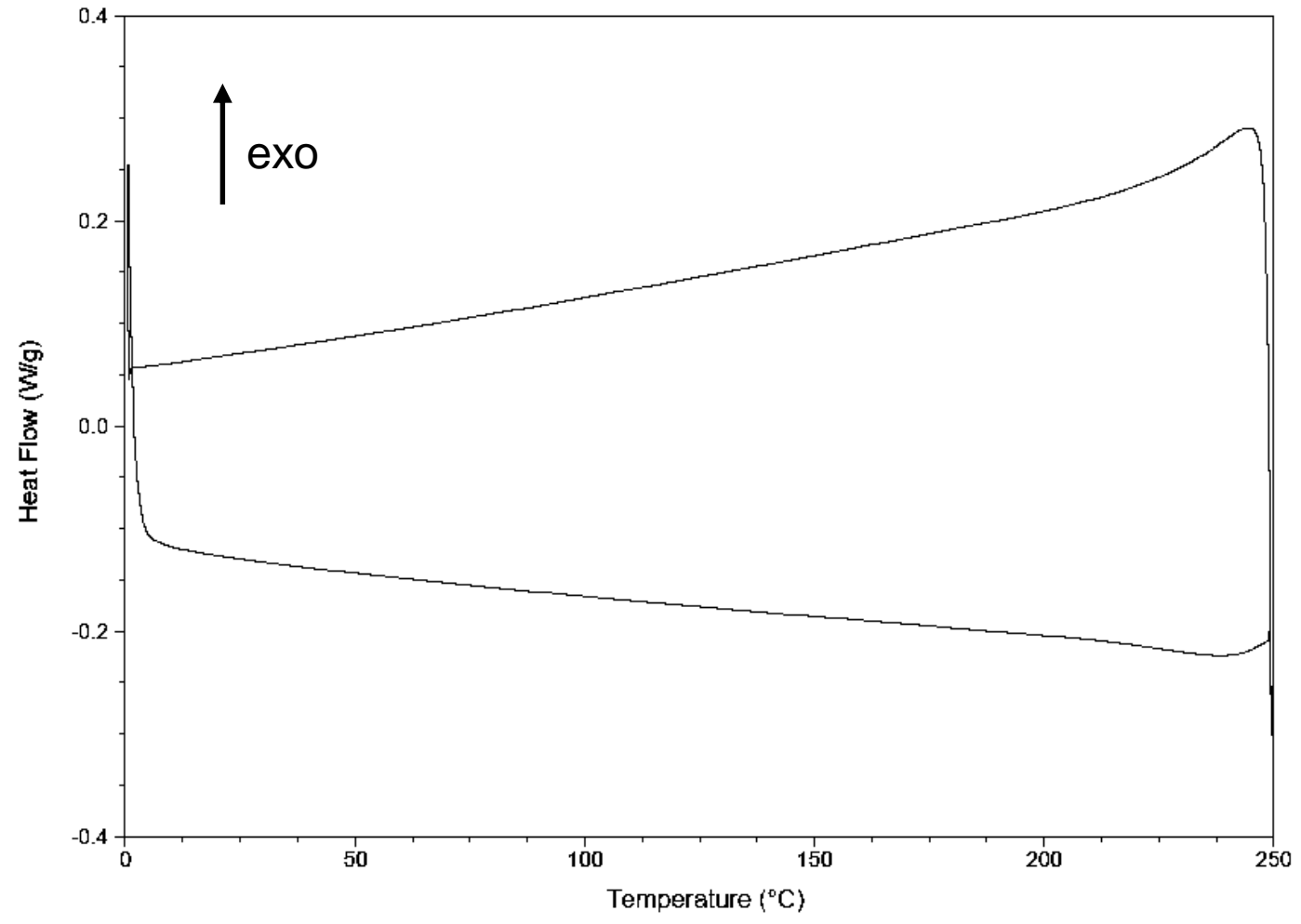

Figure S19. DSC trace for 6B. The second heating/cooling cycle is shown.

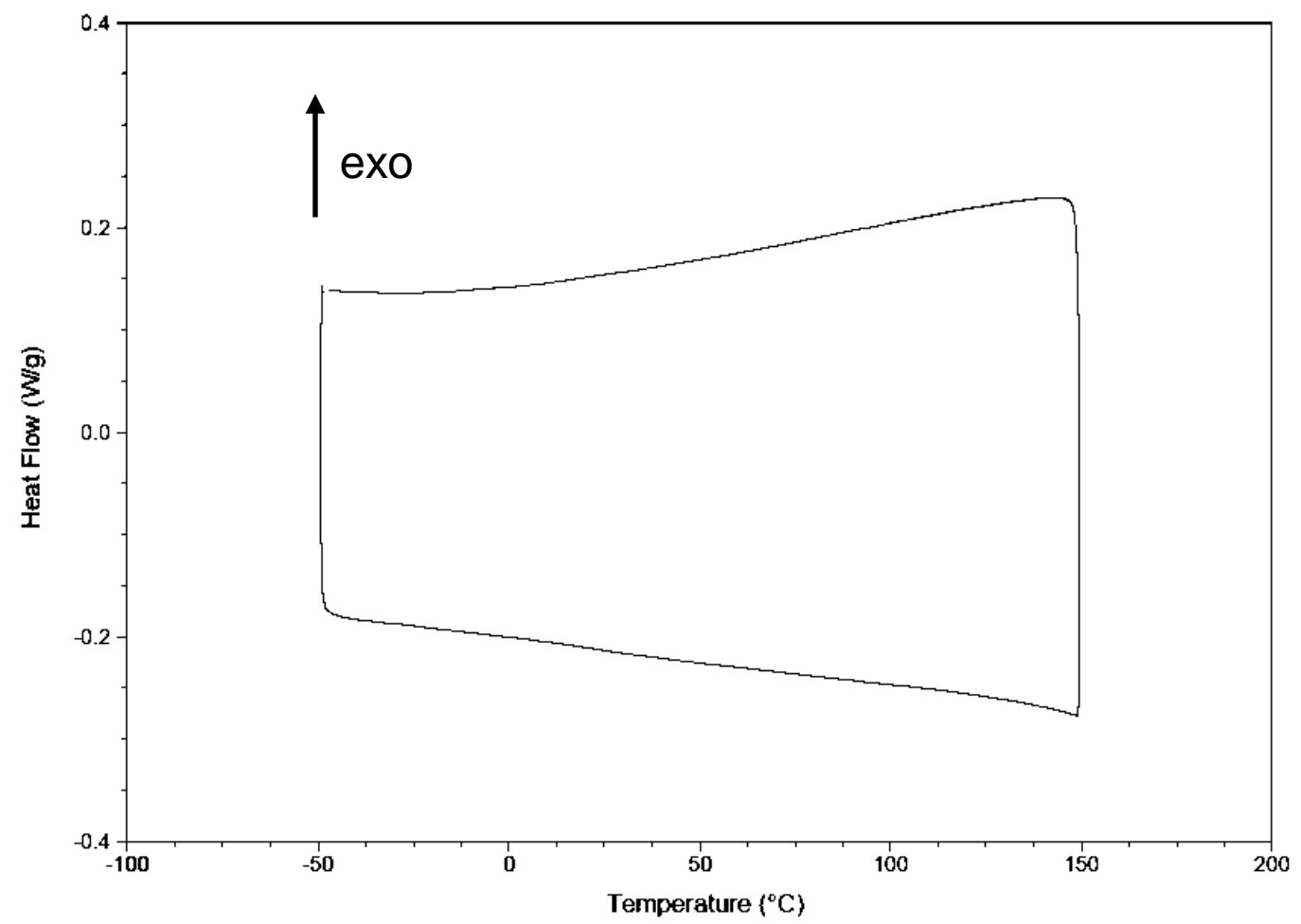

Figure S20. DSC trace for $\mathbf{6 F}-\left[\mathbf{C o}(\mathbf{C O})_{6}\right]$. The second heating/cooling cycle is shown. 


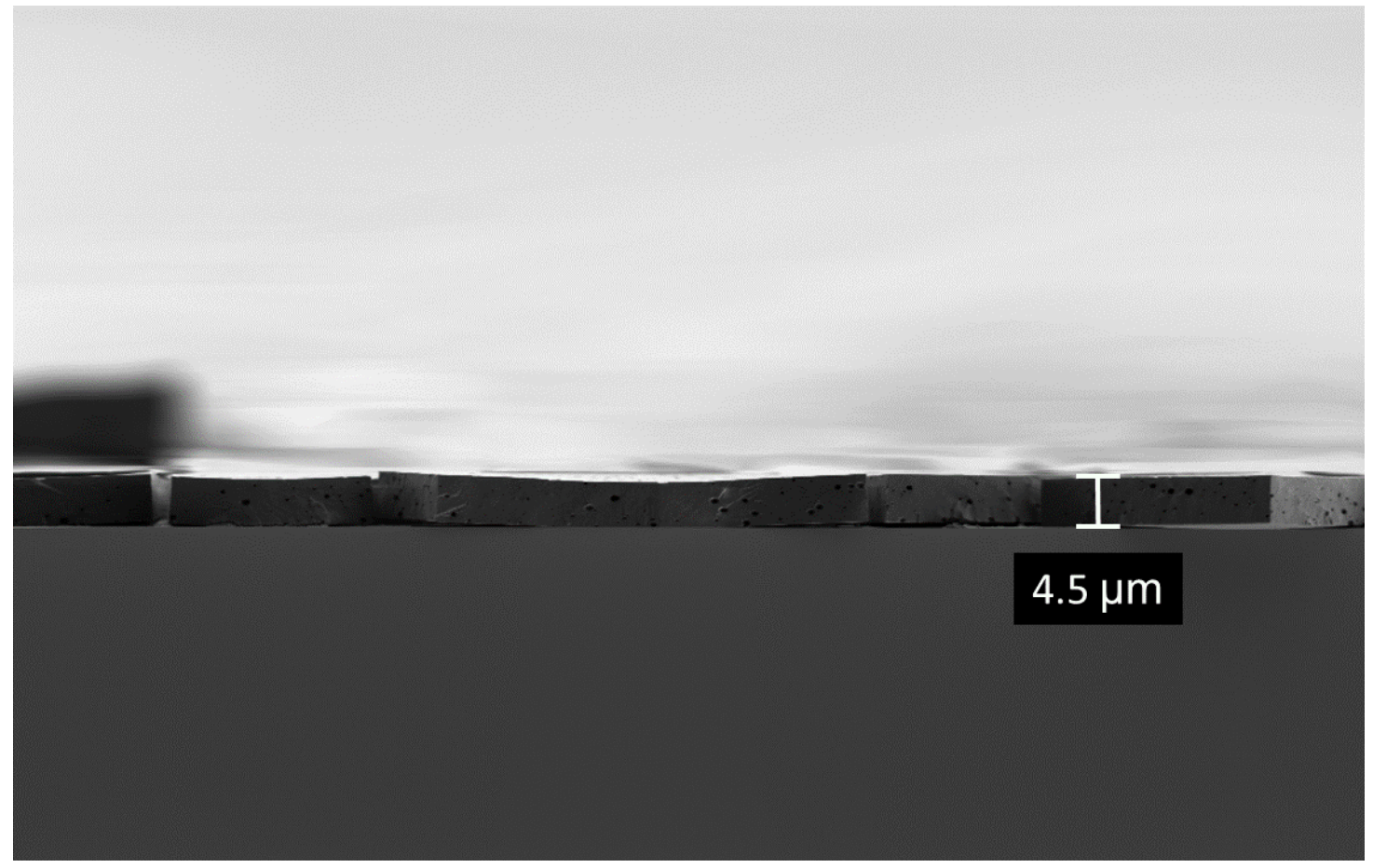

Figure S21. SEM of a cross-section of a thin film prepared by drop casting $6 \mathrm{~F}-\left[\mathrm{Co} 2(\mathrm{CO})_{6}\right]_{2}$ onto a silicon wafer.
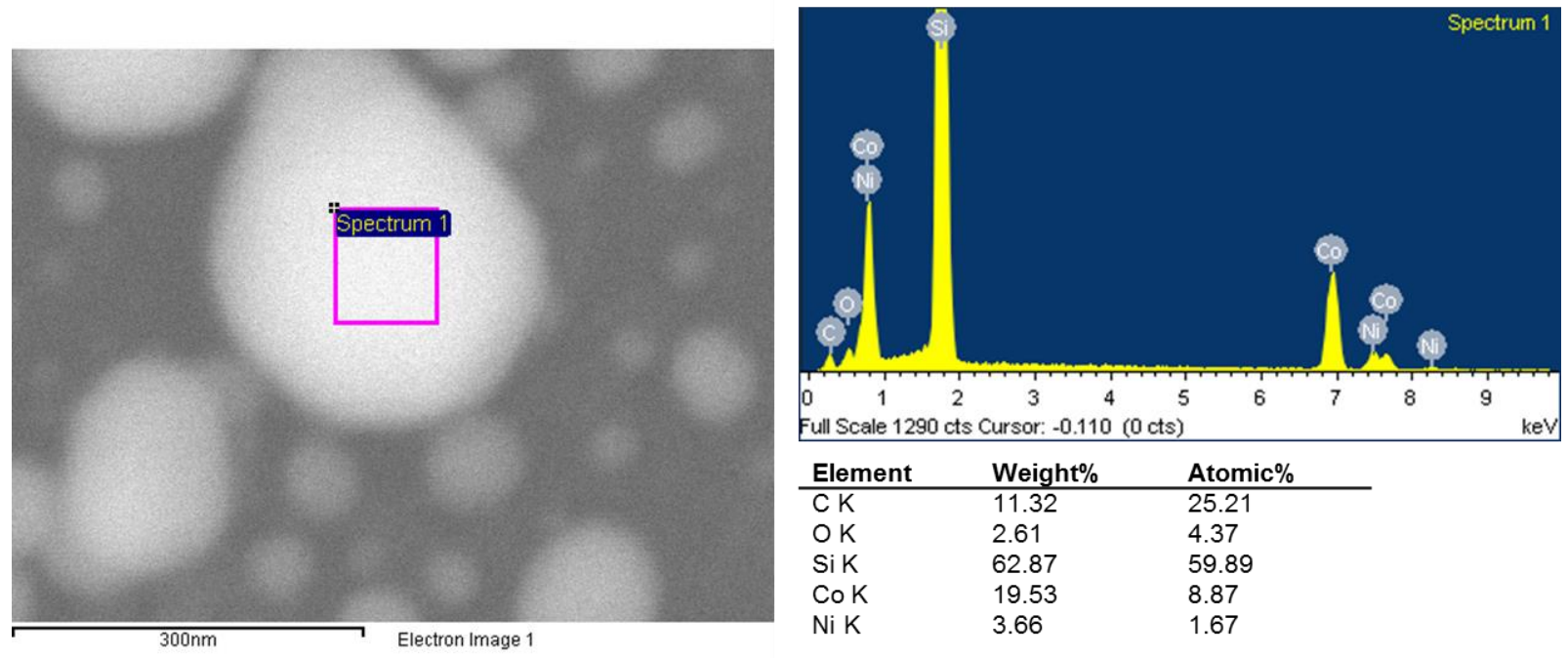

\begin{tabular}{lll} 
Element & Weight $\%$ & Atomic\% \\
\hline C K & 11.32 & 25.21 \\
O K & 2.61 & 4.37 \\
Si K & 62.87 & 59.89 \\
Co K & 19.53 & 8.87 \\
Ni K & 3.66 & 1.67
\end{tabular}

Figure S22. EDX spectroscopy data collected from the nanomaterials produced from the pyrolysis of thin film of $6 \mathrm{~F}-\left[\mathrm{Co}_{2}(\mathrm{CO})_{6}\right]_{2}$ on a silicon wafer. 